\title{
WestVirginiaUniversity
}

THE RESEARCH REPOSITORY @ WVU

Graduate Theses, Dissertations, and Problem Reports

2006

\section{Classification of dental x-ray images}

\author{
Usman Qureshi \\ West Virginia University
}

Follow this and additional works at: https://researchrepository.wvu.edu/etd

\section{Recommended Citation}

Qureshi, Usman, "Classification of dental x-ray images" (2006). Graduate Theses, Dissertations, and Problem Reports. 4258.

https://researchrepository.wvu.edu/etd/4258

This Thesis is protected by copyright and/or related rights. It has been brought to you by the The Research Repository @ WVU with permission from the rights-holder(s). You are free to use this Thesis in any way that is permitted by the copyright and related rights legislation that applies to your use. For other uses you must obtain permission from the rights-holder(s) directly, unless additional rights are indicated by a Creative Commons license in the record and/ or on the work itself. This Thesis has been accepted for inclusion in WVU Graduate Theses, Dissertations, and Problem Reports collection by an authorized administrator of The Research Repository @ WVU. For more information, please contact researchrepository@mail.wvu.edu. 


\title{
CLASSIFICATION OF DENTAL X-RAY IMAGES
}

\author{
Usman Qureshi \\ Thesis submitted to the \\ College of Engineering and Mineral Resources \\ at West Virginia University \\ in partial fulfillment of the requirements \\ for the degree of \\ Master of Science \\ in \\ Electrical Engineering \\ Dr. Hany Ammar, Ph.D., Chair \\ Dr. Robert Howell, DDS. \\ Dr. Xin Li, Ph.D.
}

Lane Department of Computer Science and Electrical Engineering Morgantown, West Virginia

2006

Keywords: ADIS, Maxilla, Mandible, ADIS, Periapical, Bitewing, crown curve, Statistical Moments, Dental Forensics, Image classification.

Copyright 2006 Usman Qureshi 


\section{ABSTRACT \\ CLASSIFICATION OF DENTAL X-RAY IMAGES \\ Usman Qureshi}

Forensic dentistry is concerned with identifying people based on their dental records. Forensic specialists have a large number of cases to investigate and hence, it has become important to automate forensic identification systems. The radiographs acquired after a person is deceased are called the Post-mortem (PM) radiographs, and the radiographs acquired while the person is alive are called the Ante-mortem (AM) radiographs. Dental biometrics automatically analyzes dental radiographs to identify the deceased individuals. While, ante mortem (AM) identification is usually possible through comparison of many biometric identifiers, postmortem (PM) identification is impossible using behavioral biometrics (e.g. speech, gait). Moreover, under severe circumstances, such as those encountered in mass disasters (e.g. airplane crashes and natural disasters such as Tsunami) most physiological biometrics may not be employed for identification, because of the decay of soft tissues of the body to unidentifiable states. Under such circumstances, the best candidates for postmortem biometric identification are the dental features because of their survivability and diversity.

In my work, I present two different techniques to classify periapical images as maxilla (upper jaw) or mandible (lower jaw) images and we show a third technique to classify dental bitewing images as horizontally flipped/rotated or horizontally un-flipped/unrotated. In our first technique I present an algorithm to classify whether a given dental periapical image is of a maxilla (upper jaw) or a mandible (lower jaw) using texture analysis of the jaw bone. While the bone analysis method is manual, in our second technique, I propose an automated approach for the identification of dental periapical

images using the crown curve detection Algorithm. The third proposed algorithm works in an automated manner for a large number of database comprised of dental bitewing images. Each dental bitewing image in the data base can be classified as a horizontally flipped or un-flipped image in a time efficient manner. 


\section{ACKNOWLEDGEMENTS}

I wish to express my gratitude to my advisor Professor Dr. Hany Ammar for his continuous support for me over many years of graduate studies; I very much appreciate his invaluable trust and best of all his great patience and tolerance. It has been my pleasure to work with a farsighted advisor like professor Ammar.

I am also very grateful to Dr. Xin Li not only for being a valuable member of my examination committee, but also for being skillful teacher of Image Processing. My gratitude also goes to Dr. Robert Howell for serving in my examination committee, providing us with a dental database and for his help in developing a better understanding of the dentistry side of the problem.

I would also like to extend my gratitude to Kimberly Mencken for her cooperation and for providing us with the CJIS dental image database and Dr. Cheri Lewis for providing us more dental records for research purposes.

I ought to thank my dear friend Ahmed Gul for his care and continuous support and I thank his mother Mrs. Maqsooda Gul for her well wishes and prayers.

I am very much indebted to my great friends: Tarik Ghanim, Cory Watson, Jawad Salimi, Rohit Seshadri, Israr Pasha, Abdul-Rehman Alsafy, Korok Biswas and Ali Askanani for their great support and valuable advice.

I would also like to express my gratitude and deep appreciation to Dr. Muhammad Chaudhry, Dr. Brian Woerner, Dr Katerina Goseva and Dr. Ramana Reddy for their valuable support in Graduate school.

I ought to thank all my WVU research colleagues: Dr. Gamal Fahmy, Satya Chekuri, Eyad Haj-Said, Mythili Ogirila, Faisal Chaudhry, Ali Bahu, Tayyeb Anwar, Tianjian Wang, and last but not the least Diaa Nassar who helped me a great deal with my research and gave me challenging tasks and the knowledge to become a better researcher. 
I am grateful to my research colleague Ayman Abaza who helped me a great deal with my research and my course work. It has also been my pleasure to cooperate with Hong Chen from MSU, Omaima Nomair, Jindan Zhou, and Hossein Mahoor from University of Miami.

Last, but by no means least, I find it an opportunity to express my love and deep appreciation to my dear family. My family has always been a source of endless support and love; I really cannot thank each of my family members enough. I must thank my Grandmother Mrs. Tawheed Qureshi, my uncle Mr. Rashid Qureshi, Mr. Iltefaat Majeed and Mr. Khalid Basharat and their families, my aunts Mrs. Naheed Qureshi, Mrs. Huma Gerdezi and Mrs. Hina Basharat for their love and support. I am very thankful to my Father Mr. Shahid Qureshi, who has been of great support to me through out my life, and to whom I owe any success I make. I thank my brother Dr. Irfan Qureshi for his guidance and for his knowledge of dentistry. 


\section{TABLE OF CONTENTS}

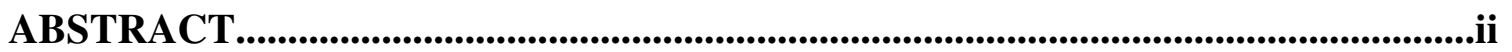

ACKNOWLEDGEMENTS ..................................................................................................ii

TABLE OF CONTENTS ......................................................................................................v

LIST OF FIGURES ................................................................................................................vii

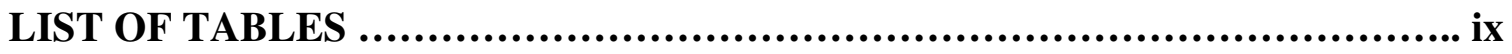

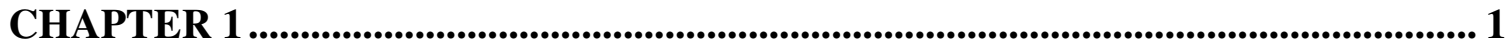

INTRODUCTION........................................................................................................................ 1

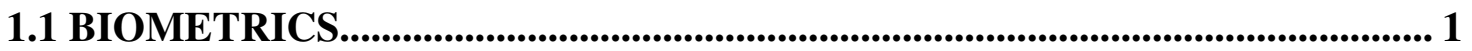

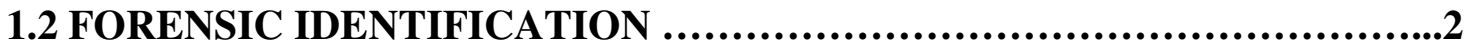

1.3 AUTOMATED DENTAL IDENTIFICATION SYSTEM.................................. 5

1.4 MOTIVATION ......................................................................................................... 15

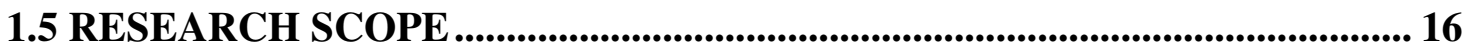

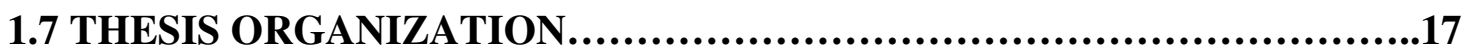

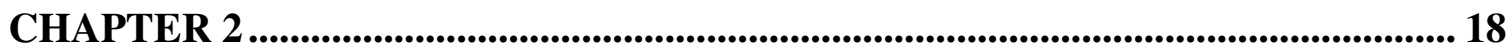

RELATED WORK AND BACKGROUND ...................................................................... 18

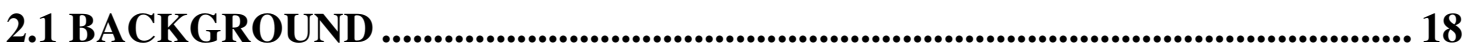

2.2 APPLICATION OF IMAGE CLASSIFICATION ................................................. 21

2.3 INTRODUCTION TO THE CLASSIFICATION TECHNIQUES ................... 23

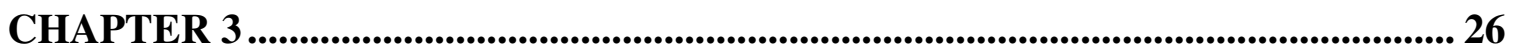

PROBLEM STATEMENT AND RESEARCH OBJECTIVES.................................... 26

3.1 PROBLEM STATEMENT ................................................................................................... 26

3.2 RESEARCH OBJECTIVES............................................................................ 27

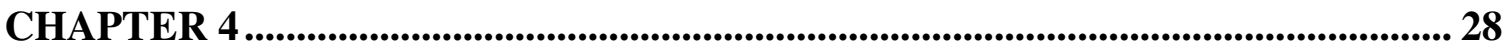

CLASSIFICATION OF DENTAL X-RAY IMAGES..............................28

4.1 CLASSIFICATION OF DENTAL PERIAPICAL FILMS ON THE BASIS OF BONE DENSITY USING TEXTURE ANALYSIS...........................28

4.2 CLASSIFICATION OF DENTAL PERIAPICAL USING THE CROWN

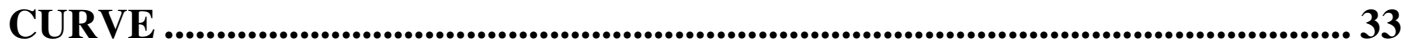

4.3 CLASSIFICATION OF DENTAL BITEWING FILMS ...................................... 42

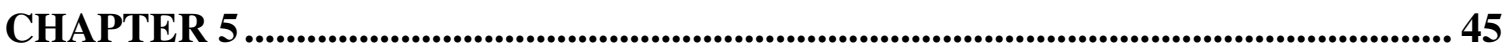

RESULTS AND ANALYSIS ......................................................................................... 45 
CHAPTER 6

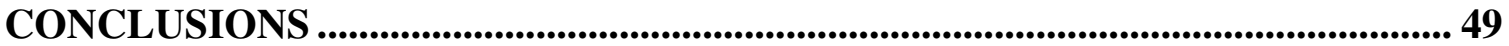

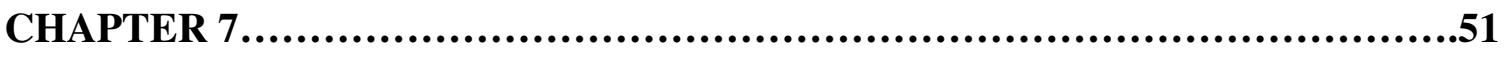

FUTURE WORK ..................................................................................................................... 51

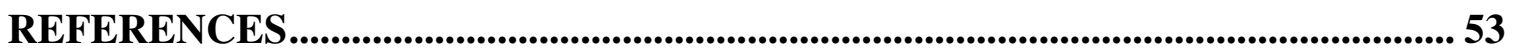

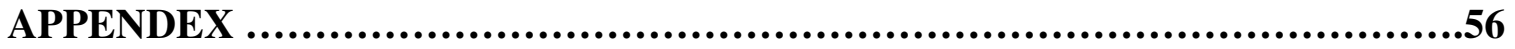




\section{LIST OF FIGURES}

Figure 1.1 Examples of Biometric........................................................2

Figure 1.2 Block Diagram of ADIS.......................................................6

Figure 1.3 Image Comparison Component..............................................8

Figure 1.4 PreProcessing Component..................................................9

Figure 1.5 Record Cropping Component................................................10

Figure 1.6 Labeled Dental Bitewing Image.........................................11

Figure 1.7 Image Enhancement......................................................12

Figure 1.8 Types of dental Films....................................................13

Figure 1.9 Teeth Labeling Component..............................................15

Figure 2.1 Shows the labeled crown and root......................................21

Figure 2.2 Shows the possible human errors in scanning periapical images..............24

Figure 2.3 Shows the possible human errors in scanning bitewing images.................25

Figure 4.1 Dental Identification of dental periapical images.........................29

Figure 4.2 Arrangement of teeth in flipped dental Periapical images.................30 
Figure 4.3 Arrangement of teeth in dental Panoramic images........................33

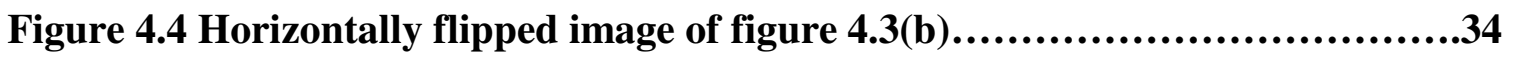

Figure 4.5 Dental Classification of periapical images.................................35

Figure 4.6 Arrangement of teeth in flipped dental Periapical images..................36

Figure 4.7 Arrangement of crown curve...........................................37

Figure 4.8 Binary images of the images in figure 4.6..............................39

Figure 4.9 Dental periapical image showing the $x$-ray holder in the bottom right...40

Figure 4.10 Dental periapical image showing the $x$-ray holder in the bottom left....40

Figure 4.11 Arrangement of crown curve dental Periapical images of figure 4.6....51

Figure 4.12 Labeled maxillary and madibular molars...............................42

Figure 4.13 Arrangement of molars in dental Bitewing images......................43

Figure 4.14 Bitewing images shows the molars around the center of the film.........43

Figure 4.15 Root regions of the upper and the lower molars in Bitewing images....44

Figure 6.1 Results after Bayesian Classification......................................46 


\section{LIST OF TABLES}

Table 1.1 Comparisons of the image segmentation techniques........................14

Table 6.1 Results of Classification of dental periapical images on the basis of bone density using texture analysis ...................................................48

Table 6.2 Results of Classification of dental periapical images using crown curve...48

Table 6.3 Results of classification of dental bitewing images...............................48 


\section{CHAPTER 1}

\section{INTRODUCTION}

Criminal investigations and law enforcement authorities have been using the personal identification systems developed during the recent years to prevent fraud and crimes.

The research work has rapidly progressed over the past years because of the escalating security concerns all over the world.

In sections 1.1 and 1.2 I give an overview of biometric identification systems. In section 1.3 I outline the research framework of the Automated Dental Identification System (ADIS), followed by motivation towards our research in section 1.4. I discuss the scope of our research in section 1.5 and section 1.6 consists of the thesis organization.

The two identification systems referred are Biometrics and Forensic Identification.

\subsection{BIOMETRICS}

Biometrics is defined as the automatic identification of a person based on his/her physiological or behavioral characteristics [Jain99]. These identification characteristics include fingerprint verification, retinal and iris scanning, hand geometry, facial recognition, signature verification etc.

These techniques were employed primarily to find the true identity of an individual in high security applications such as financial services, health care, law enforcement, Government applications, travel and immigration, criminal identification, citizen identification, E-commerce and telephony. 


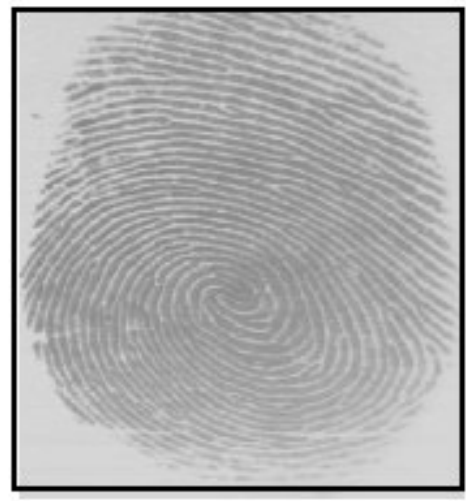

(a) Fingerprint

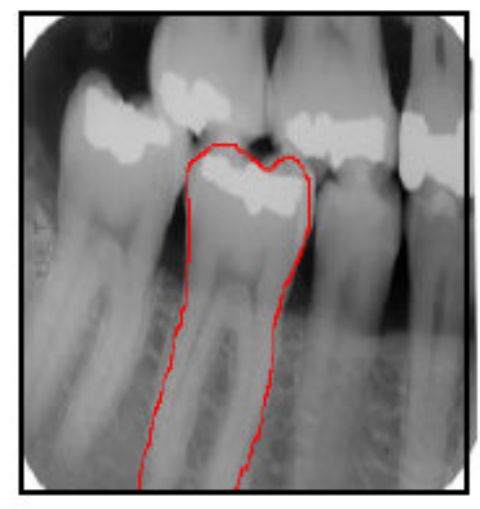

(d) Dental Features

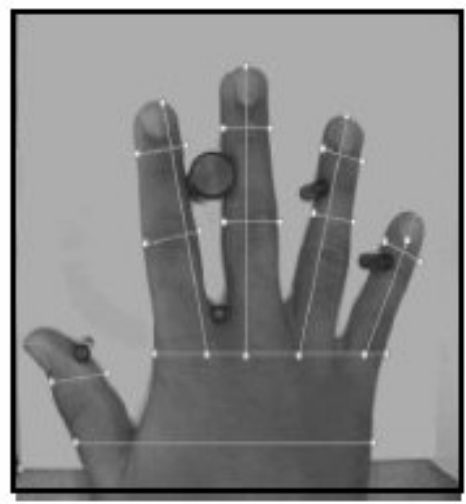

(b) Hand Geometry

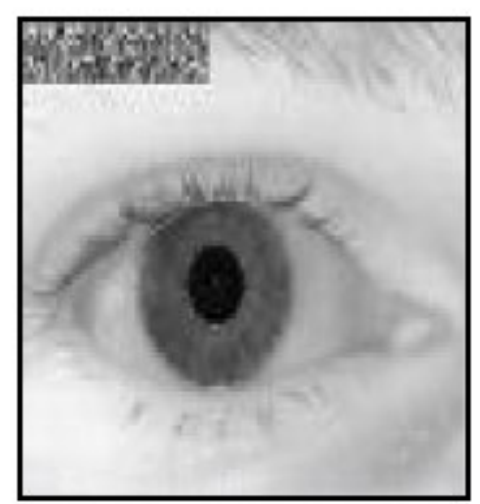

(e) Iris and Iris Code

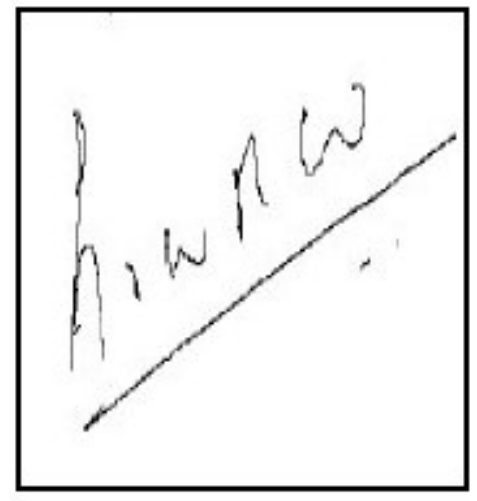

(c) Signature

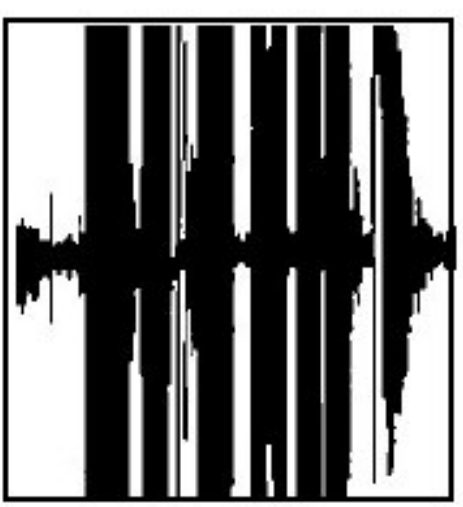

(f) Voice

Figure 1.1 Examples of Biometrics

\subsection{FORENSIC IDENTIFICATION}

Forensic identification is defined as the branch of science that uses natural sciences to help solve several legal cases and public issues. In some situations like bank robberies, homicides and kidnapping cases [RM03], the evidences found at the crime site (blood, hair, fingerprints, bullets) is considered for investigation process. Thus forensic identification comes into picture after some event has occurred.

The main difference between biometrics and forensics is that a biometric identification is used before the occurrence of an event such as gaining access to any system, verification process etc, where as forensic identification is done after the occurrence of the event like finding historical information and analyzing criminal events to help jurisdiction in 
identifying criminals [RM03]. Forensic identification prior to death is referred to as Ante mortem (AM) identification. Identification carried out after death is called Postmortem (PM) identification.

The forensic methods are used to identify the dead and missing people. Postmortem biometric identifier has to survive severe conditions like air crash disasters, delays in discovery of dead bodies and resist early decay that affects body tissues. Examples of some of the forensic identification methods are visual, finger/foot prints, DNA and dental systems.

Factors like emotional stress and constraints can affect the visual assessment of members involved in a crime scene. In the case of finger or foot prints, hazards like fire, water, mud etc. can wipe away postmortem evidences.

Dental knowledge is applied in the field of civil and criminal investigations. Most forensic scientists consider dental features acceptable for postmortem identification Forensic Odontology is defined as the identification by the use of dental features. Since the dental features are unique, i.e. no two persons can have same dental dentitions, sometimes identification may be possible with just a single tooth. Also teeth remain unaffected by fire, decomposition or any medical trauma.

This research work is one such forensic identification system called Automated Dental Identification System where dental records are taken as basis for the identification of unidentified and missing people.

There have been several attempts to develop computer-aided postmortem identification systems. The most famous among these systems are CAPMI [U.S Army90] and WinID [McGiveney]. Significant amount of human intervention is required to use the systems mentioned since none of them are fully automated. In both CAPMI and WinID, feature extraction, coding, and image comparison are carried-out manually. Moreover, the dental 
codes used in these systems are predominantly based on dental work [U.S Army90] [McGiveney].

The Computer Assisted Post Mortem Identification system (CAPMI) was developed by the bioengineering branch of the US Army Institute of Dental Research. CAPMI is a computer software program that compares between dental codes extracted from AM and PM dental records. The program matches number of dental characteristics and generates a prioritized list of candidates. This candidate list guides forensic odontologists to reference records that have potential similarity with subject records [odont]. The odontologist then completes the identification procedure by visual comparison of radiographs [U.S Army93]

WinID is a computer system that matches missing persons to unidentified persons using dental and anthropometric characteristics to rank possible matches (anthropometry is the study of human body measurements). The dental codes used in WinID are extensions of those used in CAPMI. Other information on physical appearances, pathological findings and anthropologic findings can also be added to the database of WinID. In [Nassar01], [Nassar02] the use of learnable inherent dental image features for tooth-to tooth image comparisons are proposed. The tooth-to-tooth matching problem is treated as a binary classification problem for which the parametric models of class conditional densities. Adaptive strategic searching technique is proposed and used in conjunction with back propagation in order to estimate system parameters.

A semi-automated system for human identification based on matching of teeth contours extracted from dental x-ray images is proposed in [Jain04]. The system follows three main steps for identification: radiograph segmentation, teeth contour extraction, and shape matching. For each radiograph, a human user initializes segmentation by specifying a pixel that belongs to the gap valley (an artificial curve that best separates the maxilla and mandible), then detection of the entire gap valley as well as teeth isolation are carried out using integral projection. 


\subsection{AUTOMATED DENTAL IDENTIFICATION SYSTEM}

The research of Automated Dental Identification System (ADIS) aims at developing automated system for postmortem identification of individuals by comparing their Ante mortem (AM) and Postmortem (PM) dental records. The development of ADIS is based on digital image processing techniques such as image classification, image segmentation, feature extraction, image matching etc.

Given a dental record of the subject the system aims at finding a list of candidates that possess dental features matching closely or identical to that of the subject. The forensic experts then decide which of the few candidates the subject is. The dental radiographs of a person taken from remains of death are used as Post mortem images. The PM/AM image is treated as subject image and thus a list of candidates are selected from dental records which have high similarities with that of the subject image. The Ante mortem images and Post mortem images are taken as the reference image and the input images. The input image is aligned with the images in the reference image database to find the best match.

Figure 1.2 shows the block diagram of the Automated Dental Identification System. 


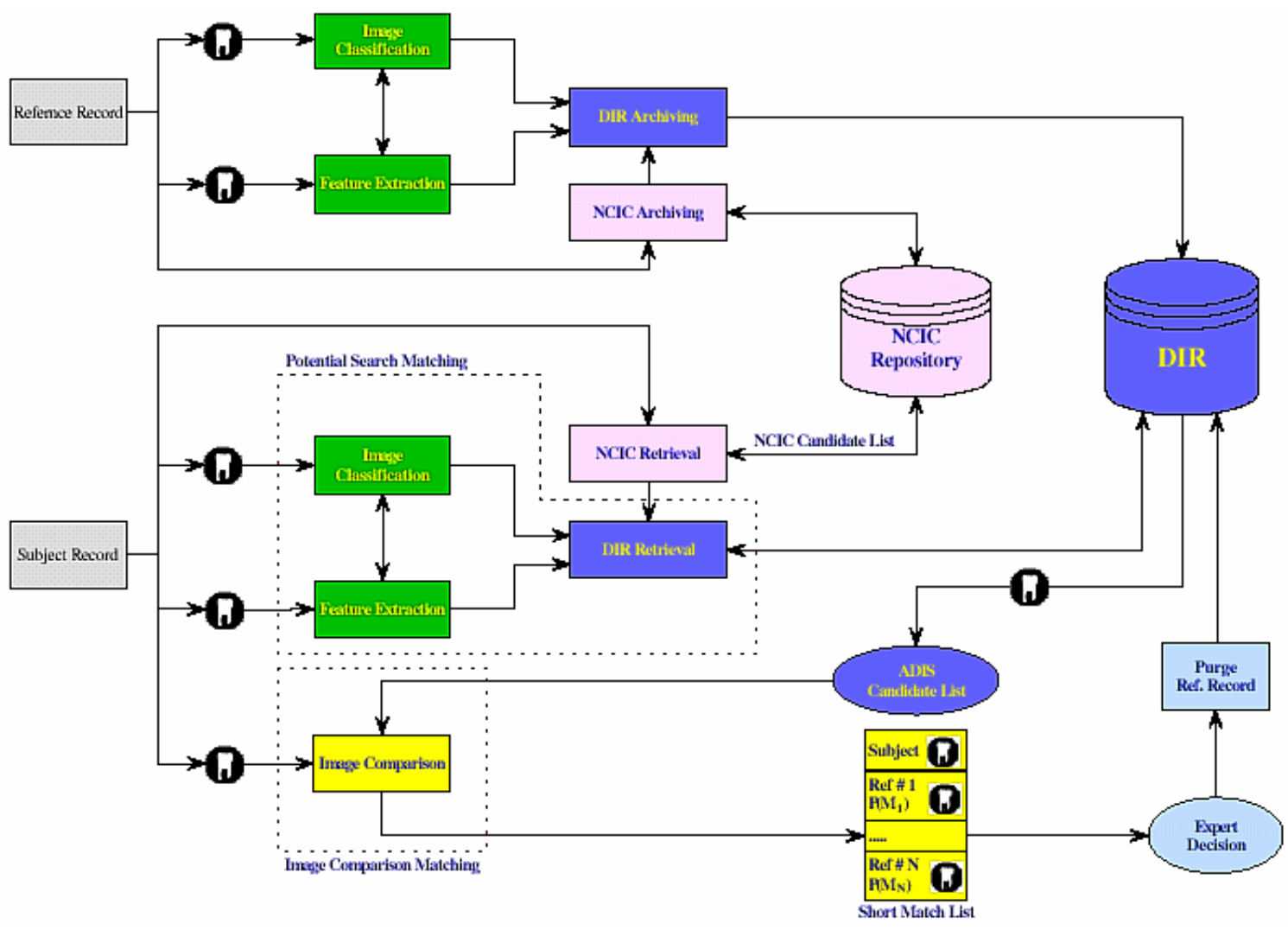

Figure 1.2 Block Diagram of ADIS

When an unidentified PM record is sub, the NCIC codes are extracted from the subject image and high level features are extracted from the images. Both these features are used to extract a list of possible images from the DIR. DIR is seen in the upper portion of the figure. It is a collection of all image files and radiographs stored on the database server. The NCIC repository shown in the figure contains technical textual dental codes. The DIR and the NCIC repository are used during several stages like image comparison, updating repositories etc.

A list of candidate records is produced by the steps mentioned above and is passed to two main components in ADIS, the potential search matching component and the image comparison matching component. The potential search matching component in the lower 
portion of the figure is based on feature extraction and archival retrieval techniques, in which a set of features are extracted from the images, encoded as a feature template, and then used as a query for searching the dental feature database for the records with the most similar features and other attributes.

Once the list of candidate images is created, it is fed to the image comparison stage that selects a smaller list of candidate images for possible positive matches with the submitted subject image. This smaller list is then given to the forensic expert who makes the final decision for positive identification. Once a positive identification is made, for a subject image, then its corresponding reference image is removed from the DIR. If a positive identification cannot be made for a subject image, then this image is added to the DIR as a new missing or unidentified image. In this system, typically if the subject record is AM, then the reference records are PM and vice versa.

\section{The Image Comparison Component [Nassar03]}

The subject images are compared with the reference images that are contained in the candidate list of ADIS. The outputs of comparison are ranked with their probability of match with the subject dental image. Comparing a pair of dental radiographs consists of two stages as follows:

a) Preprocessing the pair of radiographs

b) Decision-making

The image comparison component is shown in figure 1.3. 


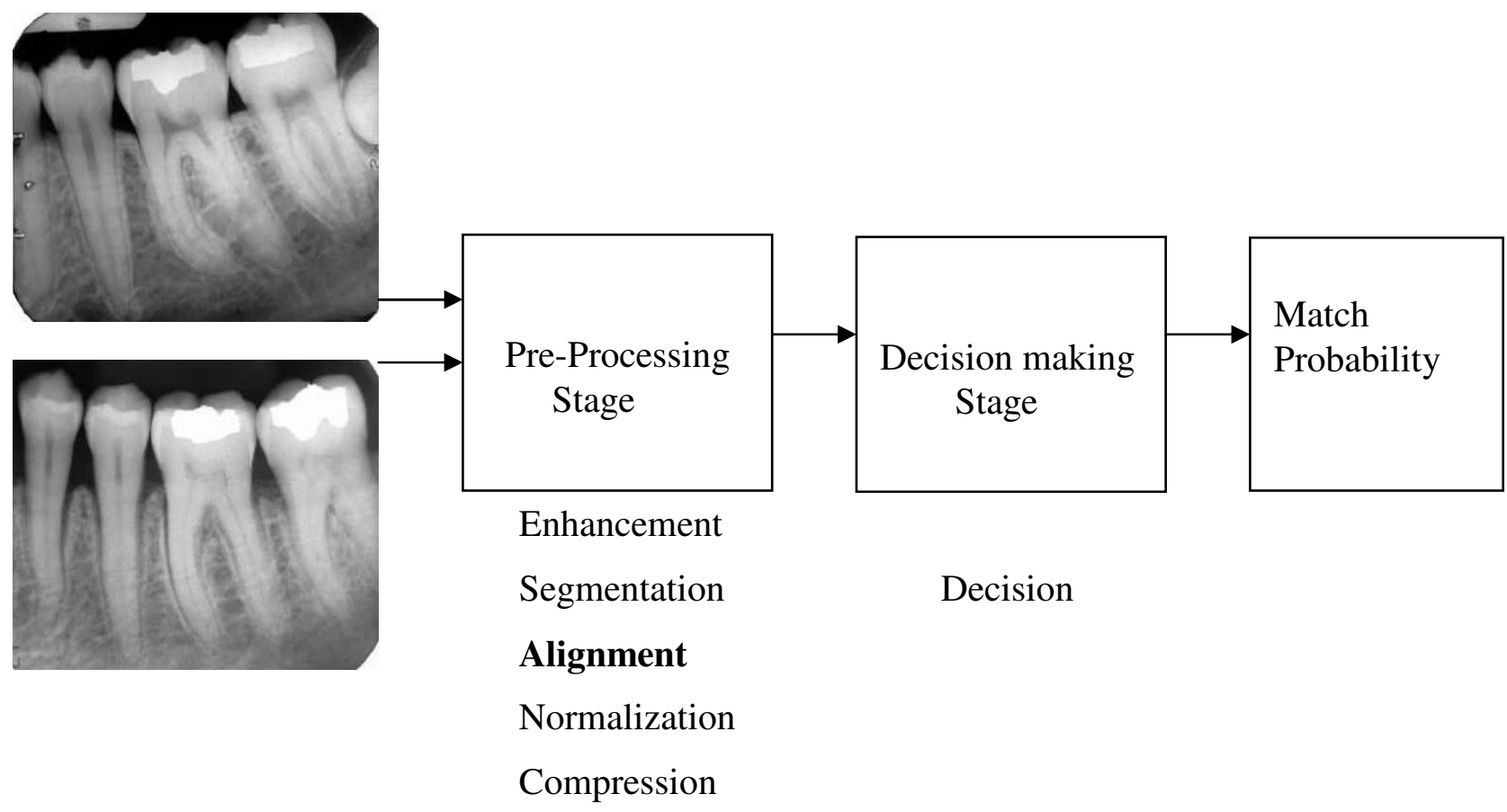

Figure 1.3 Image Comparison Component [Nassar03]

\section{Preprocessing}

The objective of the Preprocessing stage is to output a set of aligned images and compressed regions of interest (ROI) pairs with an input of two radiographic films (one from the subject record and the other from the reference record). These are then presented to the decision-making stage.

Compression removes some redundancy from the submitted pair to cut down on the computational complexity for pair matching in the decision making stage [Nassar03].

The preprocessing component handles the following tasks: (a) records cropping into dental films [Li06], (b) enhancement of films to compensate for possible poor contrast 
[Zhou05], (c) classification of films into bitewing, periapical, or panoramic views

[Zhou05], (d) segmentation of teeth from films [Zhou05], and (e) annotating teeth with labels corresponding to their location [Mahoor05].

Each task is a separate module, that has specific inputs and outputs, and for some tasks I have many realizations.

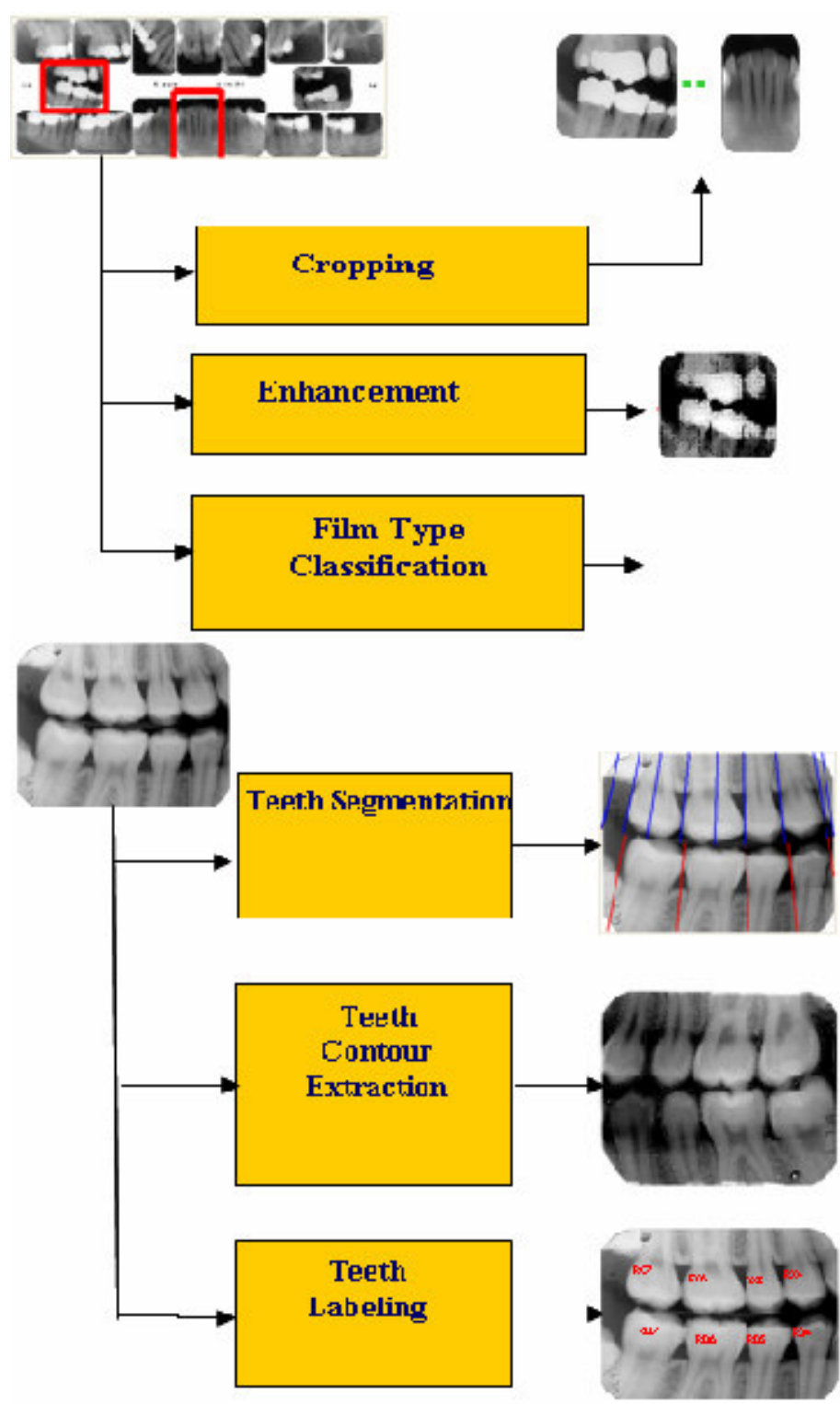

Figure 1.4 PreProcessing Component [Nassar03] 


\section{Cropping}

I focus on cropping problem of dental X-ray records and strive to achieve a good trade of between accuracy and complexity. I want cropping results to be as accurate as possible since inaccuracy in cropping of dental records is likely to hinder the performance of subsequent processing steps and accordingly the overall performance of the entire identification system.

A three-stage approach for cropping as depicted in Fig. 1.5: First a preprocessing stage whereby the background layer of the image record is extracted, extract connected components and classify them as either round-corner or right-corner connected components. The second stage is the arch detection stage and dimension analysis stage.. The third stage is a post processing stage that performs topological assessment of the cropping results in order to eliminate spurious objects.

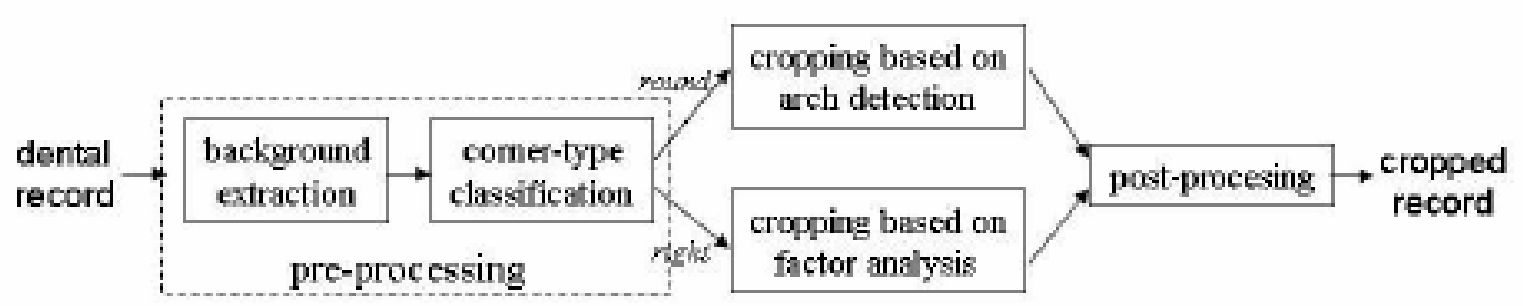

Figure 1.5 Record Cropping Component [Li06]

\section{Enhancement}

Dental radiographs often suffer from low contrast and poor technique of radiography that complicate the task of segmentation. I strive to achieve accuracy in enhancement since applying enhancement usually helps the segmentation. Dental radiographs have three distinctive regions: background (the air), teeth, and bones (see Fig. 1.6). Usually the teeth regions have the highest intensity, the bone regions have high intensity that sometimes is 
close to that of the teeth, and the background has a distinctively low intensity. In order to prepare the image for successful segmentation, the first step is to enhance the image's contrast by making the teeth regions brighter and suppressing the intensity in the bone and the background regions.

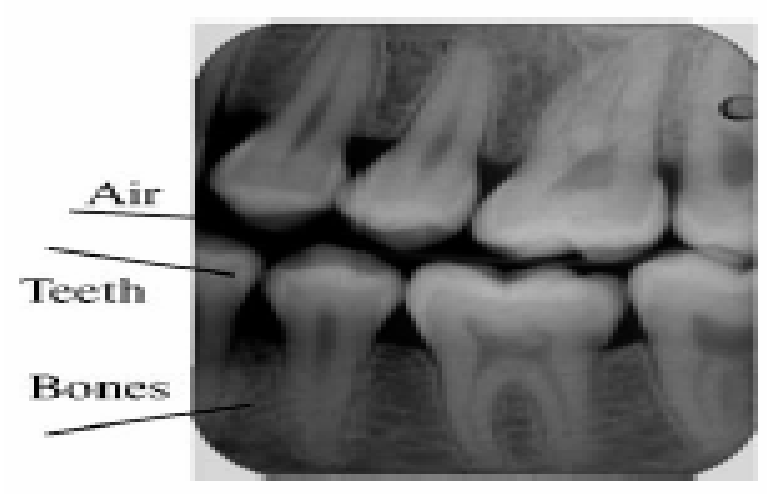

Figure 1.6 Labeled Dental Bitewing Image

The method used applies a top-hat and bottom-hat filtering operations on the original image. The enhanced image is obtained by adding to the original image the result of the top-hat filter and subtracting the result of the bottom-hat filter, as follows: EnhancedImage $=$ OriginalImage + top-hat(OriginalImage $)$ - bottom-hat(OriginalImage) . Fig. 1.7 shows an example of applying the above enhancement algorithm on a bitewing dental image. 


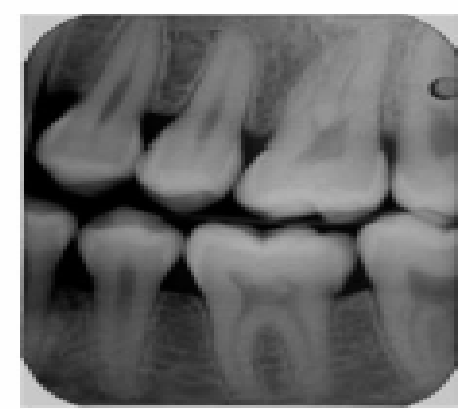

(a)

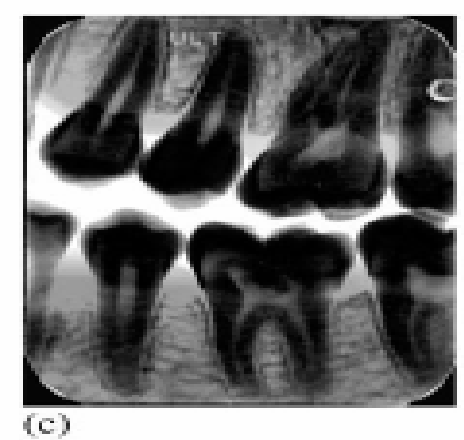

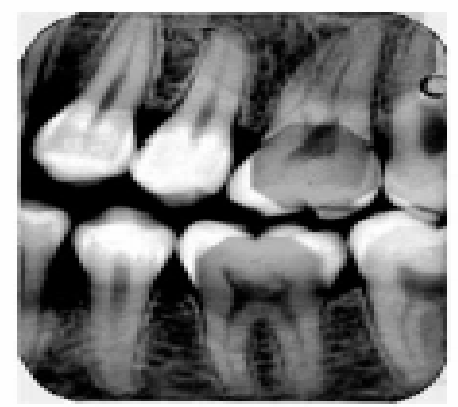

(b)

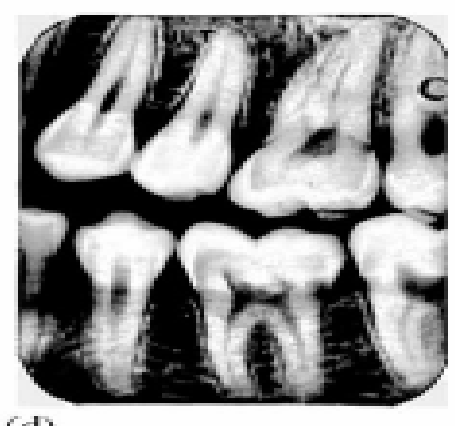

(d)

Figure 1.7 Image Enhancement

(a) Original Image

(b) Image after applying top hat filer

(c) Image after applying bottom hat filer

(d) Enhanced Image

\section{Classification of Images as Bitewing, Periapical or Panoramic Views}

In the ADIS system, there are three types of dental images according to the way they capture the dental features, i.e., panoramic, periapical and bitewing (see Fig. 1.8). The periapical images are further sub classified into upper periapical, which shows the upper jaw, and lower periapical, which shows the lower jaw. Different types of dental radiographs contain different information of dental features. Given a dental image, a Bayesian classifier [Duda00] is used to classify the dental image. 


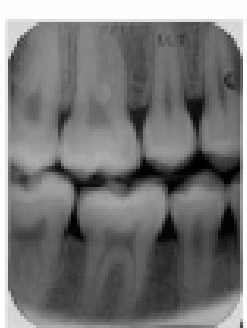

(a)

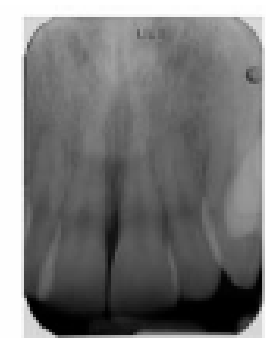

(b)

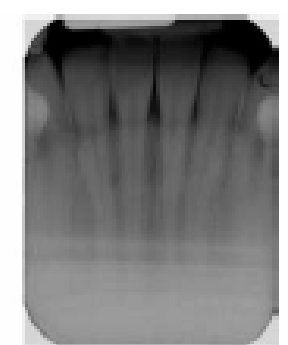

(c)

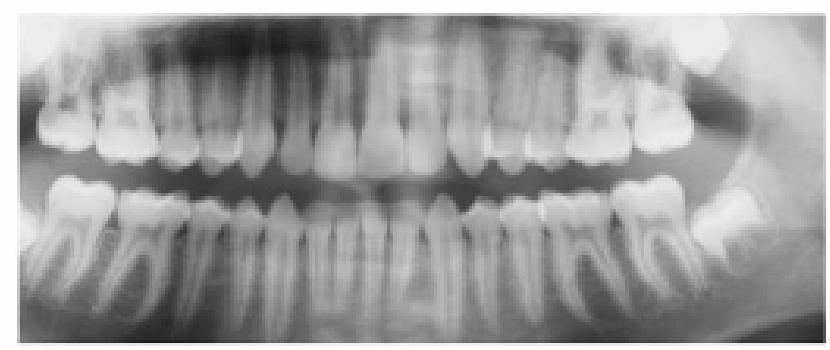

(d)

Figure 1.8 Types of dental Films

(a) Dental Bitewing Image

(b) Dental Periapcial upper

(c) Dental Periapical Lower

(d) Dental Panormanic

\section{Segmentation}

The goal of segmentation method is to segment the teeth from the background, in bitewing images, and extract for each tooth the contour of the crown and the root. In [Nassar02], [Nomair05] and [Said06], the researchers introduced different approaches for dental image segmentation problem. The performance of various segmentation algorithms based on the performance evaluation methodology is proposed in [Nassar04].

An experiment that used set of 500 bitewing dental radiographic films selected from large dental radiographic databases [CJIS00] [CJIS02] was conducted. A brief comparison among the five algorithms is shown in table 1.1 . 


\begin{tabular}{|c|c|c|c|c|c|}
\hline Algorithm & Principles & Types of views & Is it automated? & $\begin{array}{c}\text { Optimality } \\
\text { Failure } \\
\text { rate }\end{array}$ \\
\hline $\begin{array}{c}\text { Jain and Chen } \\
\text { [Jain04], }\end{array}$ & Integral projection & $\begin{array}{c}\text { Bitewing and } \\
\text { Panoramic }\end{array}$ & $\begin{array}{c}\text { No, semi- } \\
\text { automated }\end{array}$ & $61.85 \%$ & $2.61 \%$ \\
\hline $\begin{array}{c}\text { Nomair and } \\
\text { Abdel-Mottalb } \\
\text { [Nomair05] }\end{array}$ & $\begin{array}{c}\text { Iterative and adaptive } \\
\text { thresholding, integral } \\
\text { projection }\end{array}$ & Bitewing only & Yes & $19.24 \%$ & $11.8 \%$ \\
\hline $\begin{array}{c}\text { Zhou and Abdel- } \\
\text { Mottaleb } \\
\text { [Zhou05], }\end{array}$ & $\begin{array}{c}\text { Morphology, adaptive } \\
\text { threshold, integral } \\
\text { projection }\end{array}$ & Bitewing only & Yes & $28.84 \%$ & $3.47 \%$ \\
\hline $\begin{array}{c}\text { Haj Said, Nassar, } \\
\text { Fahmy, and } \\
\text { Ammar } \\
\text { [Said06], }\end{array}$ & Morphology & Bitewing and & Periapical \\
\hline $\begin{array}{c}\text { Haj Said, Nassar, } \\
\text { and Ammar } \\
\text { [Nassar04], }\end{array}$ & Connectivity properties & Bitewing & Yes & $30.40 \%$ & $1.141 \%$ \\
\hline
\end{tabular}

Table 1.1 Comparisons of the image segmentation techniques

\section{Teeth Labeling}

I present an algorithm for the classification and numbering of teeth to be used during archiving and retrieval in or from the database. The algorithm starts by classifying each tooth in a bitewing image based on its inherent shape and then it considers the relationship between the neighboring teeth in the bitewing image to correct any initial misclassification. Finally, using the results of the classification, it assigns a number to each individual tooth based on the common numbering system of dentistry [Brogdon98].

Figure 1.9 shows our method for the classification of teeth in bitewing images. The method has three main steps: Teeth segmentation, Bayesian pre-classification using Fourier descriptors of each tooth contour, and final classification and numbering. 


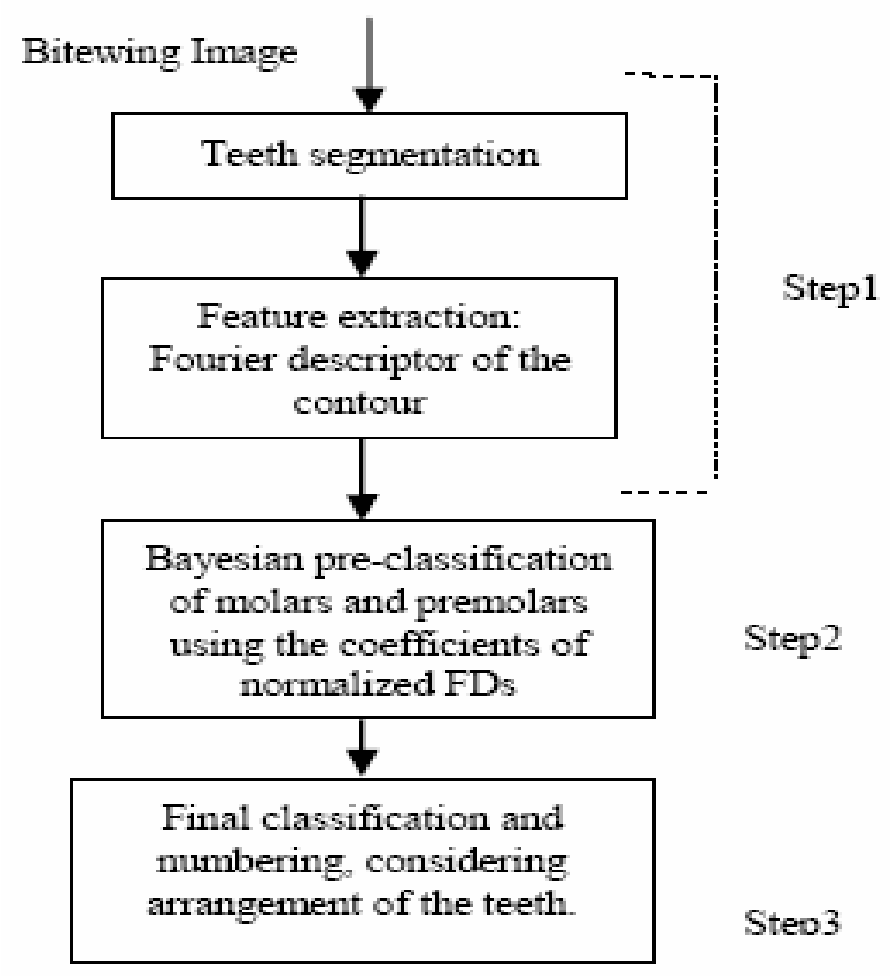

Figure 1.9 Teeth Labeling Component

\section{Decision making}

The probability of match between subject and reference films based on comparison of features extracted from both films is determined by the decision making stage.

\subsection{MOTIVATION}

In this thesis I am motivated to study the image classification step to develop a fast and robust algorithm for an efficient classification of the dental periapical and dental bitewing images. Throughout the remainder of this thesis I use the terms subject, query, and input images interchangeably to refer to a subject image which is to be classified. I emphasize on accuracy and speed to develop a competent approach to obtain desired classification results. 


\subsection{RESEARCH SCOPE}

The work in this thesis is limited to Classification of 2 types of dental radiographs. I consider Texture, crowns, and roots during the classification of image. Thus specific algorithms need be used for specific type of subject image.

\subsection{SUMMARY AND CONTRIBUTIONS}

The texture analysis technique for the classification of dental periapical images is a frequently used approach based on the statistical properties of the intensity histogram. One class of such measures is based on statistical moments. Mean Standard deviation, smoothness, skewness, uniformity and entropy [gonza02]. The 6 statistical moments of the bone texture are used in the Bayesian classification for training and testing purposes. Experiment was conducted by training the system according to the Bayesian classification with 55 maxilla images and 55 mandible images (see appendix $\mathrm{A}$ and appendix B). Testing was done according to the Bayesian classification on 95 maxilla images and 95 mandible images (see appendix $\mathrm{C}$ and appendix D). The experiment shows that our method is capable of classifying whether a dental periapical image is of a maxilla or a mandible with $72 \%$ accuracy even if the images are horizontally flipped (see table $6.1)$

In the second classification technique for the dental periapical images I make use of the crown curve. The top part of the crown of each tooth connects to the top part of the crown with its neighboring teeth and displays a line which I call the crown curve. I use location and orientation information of edge points of the crowns as features and I use distance measurements to compute the convexity or the concavity of the crown curve under observation. Testing results based on 190 periapical images suggest that our algorithm converges to correct solutions in more than $82 \%$ of the test cases (see table $6.2)$. 
Classification of dental bitewing images is carried out by using the mean value around the roots of the molars in the upper and the lower jaws for classification. The test set is based on 495 dental bitewing images out of which 245 are horizontally flipped (the upper jaw looks like the lower jaw and the lower jaw looks like the upper jaw) and 250 are unflipped. Testing results based on these 495 bitewing images suggest that our algorithm converges to correct solutions in more than $79 \%$ of the test cases. The time taken to classify 495 bitewing images as horizontally flipped/rotated or un-flipped/un-rotated images is almost 17 seconds (see table 6.3).

\subsection{THESIS ORGANIZATION}

The remaining chapters of the thesis are organized as follows. In chapter two I give a description about the previous research. Chapter three contains a brief description stating the problem and the research objectives. In chapter four I demonstrate our approach in a detailed manner consisting of inputs, theory of approach, bounds on parameters and the implemented technique. I also present diagrams and flow charts depicting various concepts. Chapter five presents testing methods and investigates the results. In chapter six and seven I discuss conclusions to our approach and predict the scope of future work. 


\section{CHAPTER 2}

\section{BACKGROUND}

There has been no known related work, for images to be classified as the maxilla or mandible periapical images or horizontally flipped or un-flipped bitewing images. In this chapter I present a background of the dental and radiographic properties of the images in section 2.1. In section 2.2 I introduce the techniques used for the classification.

\subsection{BACKGROUND}

The AM and PM dental radiographs used for the identification of individuals in ADIS are mainly of two types.

(i) Dental Periapical Radiographs

(ii) Dental Bitewing Radiographs

\subsubsection{PERIAPICAL RADIOGRAPHY}

In periapical radiographic technique, Periapical films are used to record the crown, root and periapical regions of teeth. Periapical films are available in 3 sizes [Kumar04]. Size 0-for small children (pedo film) 22 x $35 \mathrm{~mm}$

Size 1 -for adult anterior projections $24 \times 40 \mathrm{~mm}$

Size 2-standard films for adults $\quad 32 \times 41 \mathrm{~mm}$

\section{INDICATIONS FOR PERIAPICAL RADIOGRAPHS}

(a) To evaluate the dental carries.

(b) To evaluate the periapical infections. 
(c) To evaluate the periodontal diseases.

(d) To evaluate the mixed dentition analysis.

(e) Assessment of root morphology before extraction.

(f) To evaluate the small neoplasm and cysts especially in periapical region.

(g) To evaluate the pathology of bone in periapical area.

(h) To evaluate the pulpal calcification and pulp stones.

(i) To evaluate the dental anomalies.

(j) Assessment of working length in endotreatment.

(k) To evaluate the impacted teeth.

\section{LIMITATIONS}

(a) In patients with difficulty in opening the mouth (trismus).

(b) Patient with gagging sensation while taking posterior region of teeth.

(c) Larger cyst and tumor that cannot be covered completely by periapical film.

\subsubsection{BITEWING RADIOGRAPHY}

In this radiographic technique periapical films are used to record the coronal portions of the maxillary and the mandibular teeth in one image (see figure 4.14). In adult size 2 periapical films and size 1 for children's are used to take bitewing projection [Kumar04].

Bitewing films have a paper tab projecting from the middle of the middle of the film on which the patient has to bite to support the film. 


\section{INDICATION FOR BITEWING RADIOGRAPHY}

(a) Mainly used to detect interproximal carries.

(b) To evaluate height of the alveolar crest in assessment of periodontal disease.

(c) Monitoring the progression of dental carries.

\subsubsection{DIFFERENCES BETWEEN UPPER AND LOWER JAWS}

The bone density in the lower jaw bone (mandible) is higher than the bone density in the upper jaw bone (maxilla). The maxilla has spongy bone and more blood supply, where as the mandible has less spongy bone and more cortical bone which makes the mandible more dense and appears darker compared to the spongy bone on the X-ray [Kumar04]. There are 4 levels of density defined for the jaw bone, D1, D2, D3 and D4. D1 stands for Dense cortical, D2 stands for Porous cortical and course trabecular, D3 stands for porous cortical (thin) and D4 stands for fine trabecular. The anterior maxilla is usually $\mathrm{D} 2$ or D3, the posterior maxilla is D3 or D4, in the mandible the anterior mandible is D1 or D2 where as the posterior mandible is D2 and D3 or a mixture of both types [Ash05]. Other than this in the upper jaw I have the maxillary sinus that can be seen at times especially when a panoramic radiograph is taken, due to the presence of this maxillary sinus the maxillary bone becomes less dense. In our first technique, I use bone density to classify images.

There are 2 main visible parts of a tooth, the crown and the root [Ash05]. The crown is the part shown outside the bone where as the root is inside the bone figure 2 . The crowns, combined together display a curve which is the principle feature in our second algorithm to classify the dental periapical image.

The molars have 2 roots in the mandible and three in the maxilla, a hazy palatal root is the third one which is either superimposed or seen in the center of the bifurcation of the 
two roots in the maxillary molars. This third root causes the maxillary molars to appear less dense on a radiograph than the mandible molars [Ash05]. The mean value of the pixels is greater in the maxillary molar as compared to the mandible molar because of the presence of the third root in the maxillary molar. Our third algorithm that classifies the dental bitewing images is based on the higher mean value of the pixels around the molars.

In our work I deal with dental periapical and dental bitewing images. These images contain a fair amount of bone, crowns and molar teeth to be analyzed.

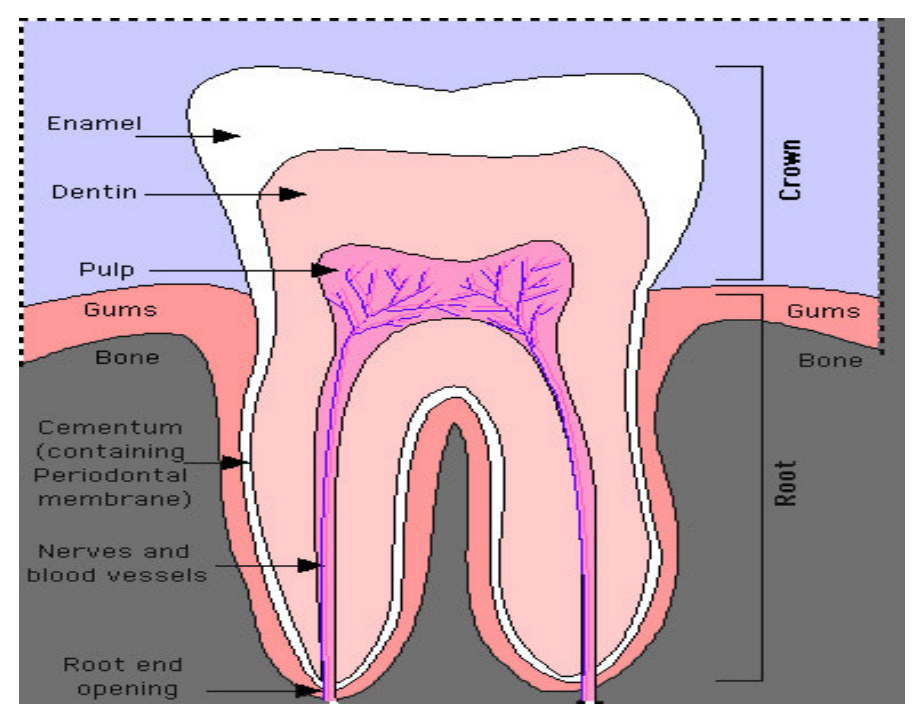

Figure 2.1 Shows the labeled crown and root.

\subsection{APPLICATION OF IMAGE CLASSIFICATION}

Here I present some fields where image classification is being utilized.

Biometric \& Forensic systems: As discussed in the earlier chapter, image registration plays a significant role in providing successful solutions to the field of certain biometric systems for tracking of characteristics of individuals and locating patterns such as finger printing, retinal features, signature verification, character recognition and facial recognition [Brown92]. 
Computer vision: Classification of images taken from different viewpoints finds applications in depth and shape reconstructions for stereo mapping in the field of computer vision and tracking object motion. Automatic detection of change for security monitoring, target template matching with real time images and quality inspection are the other applications of image classification in the field of computer vision. [Brown92] [Zitova03]

\section{Medical Image Registration [Kneöaurek00]}

Image classification plays a vital role in the field of medicine. Some areas of medicine where image registration is used are discussed below.

a) Medical diagnosis requires usage of SPECT and PET. Uncertainty in the anatomic definition on SPECT and PET images, however, sometimes limits their usefulness. To overcome this problem, a combination of magnetic resonance images (MRI) and X-ray computed tomography (CT) images with functional SPECT or PET images of the same sections of the body is used. This provides complementary anatomic (MRI or CT) and physiological (SPECT or PET) information useful for research, diagnosis, and treatment [Kneöaurek00].

b) Early detection of cancers is another major application of image classification. It also works as a visualization tool that can significantly aid in the early detection of tumors and other diseases, and aid in improving the accuracy of diagnosis.

c) Diagnosis of breast cancer, colon cancer, cardiac studies, wrist and other injuries, inflammatory diseases, different neurological disorders including brain tumors, Alzheimer's disease and schizophrenia, radiotherapy for brain tumors etc are dealt using image registration. [Kneöaurek00].

Other applications: Other applications include classifying images from various electromagnetic bands like in microwave, radar, and scene classification such as classifying buildings, roads, vehicles and surveillance of nuclear plants. 


\subsection{INTRODUCTION TO THE CLASSIFICATION TECHNIQUES}

There are three kinds of errors made by humans while scanning a dental x-ray.

(i) The dental x-ray might be flipped horizontally before scanning.

(ii) The dental $\mathrm{x}$-ray might be flipped vertically before scanning.

(iii) The dental $\mathrm{x}$-ray might be rotated before scanning.

In my first technique to classify dental periapical image as maxilla or mandible I start by cropping the regions of bone in an image and then calculating statistical moments of texture for the bone. I finally use the texture measurements to identify the image as a maxilla (upper jaw) or a mandible image (lower jaw). In figure 2.2 we see the three kinds of scanning errors in $\mathrm{x}$-rays mentioned above. The texture analysis technique works efficiently if there is a scanning error present in the Image but is not responsible for detecting the type of scanning error present in a periapical image.

In our second technique for the dental periapical images, I identify whether a given dental periapical image is of a maxilla or a mandible by first identifying if the image looks like a maxilla or a mandible. The image is converted to binary image with a threshold. The smaller edges are discarded and the longer edges are preserved to develop the crown curve. The curve of the crowns is examined for a falling or a rising edge anywhere in the curve. Finally the curve of the crowns is used for classifying the image as a maxilla or a mandible. In figure 2.2 we see three kinds of scanning errors mentioned above. The crown curve technique works efficiently if there is a scanning error present in the Image but is not responsible for detecting the type of scanning error present in a periapical image.

In our technique for the dental bitewing images, I start by calculating the mean of the lower region that usually contain the molars followed by calculating the mean of the upper region that usually contain the molars. The mean of the two regions are compared and the classification is done accordingly. In figure 2.3 we see three kinds of scanning errors made by humans while scanning a dental Bitewing x-ray. This technique works 
efficiently if there is a scanning error present in the Image but is not responsible for detecting the type of scanning error present in a bitewing image.

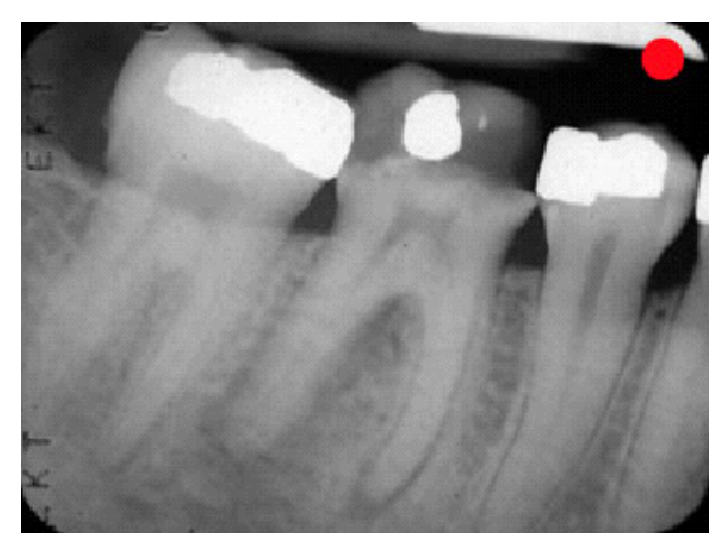

(a)

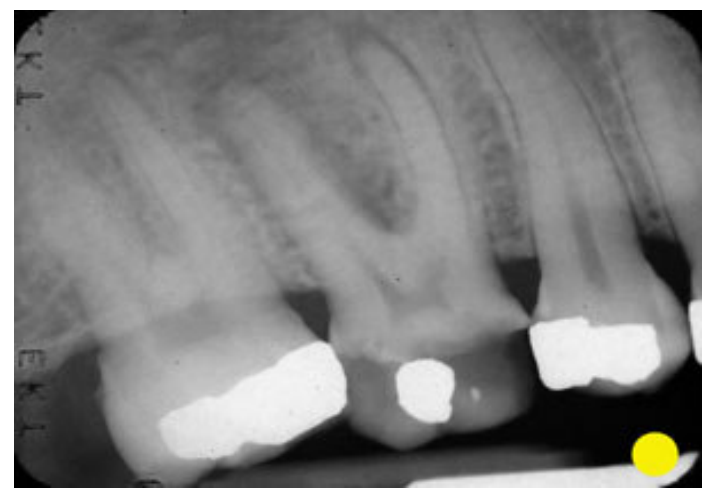

(c)

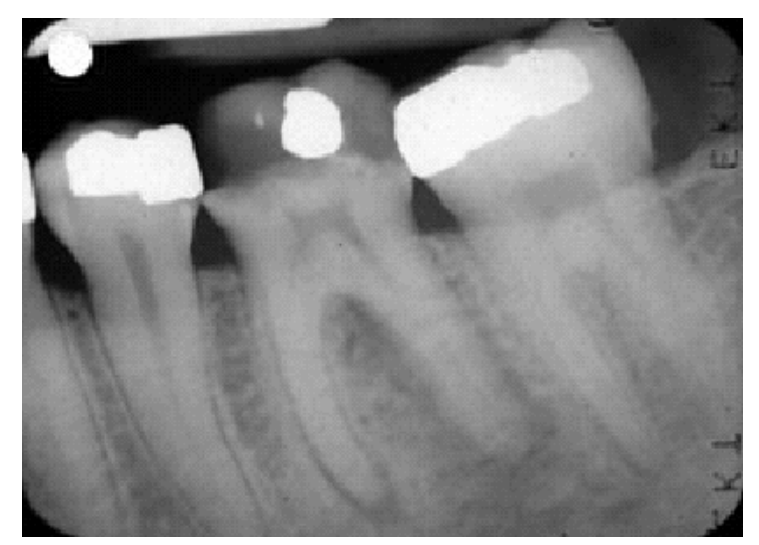

(b)

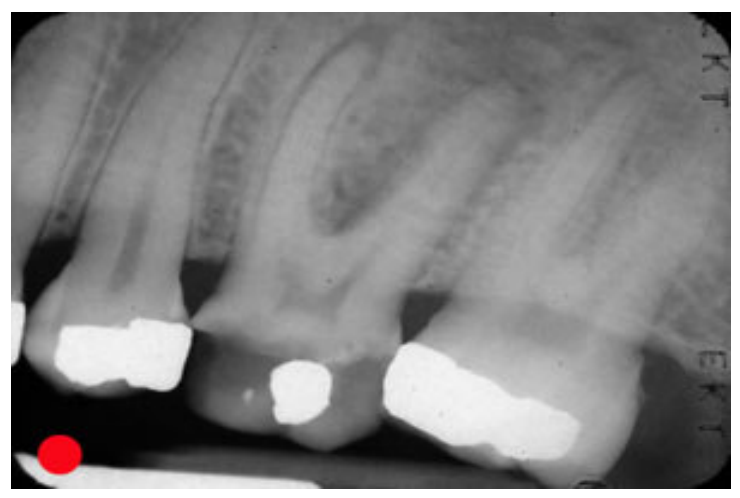

(d)

Figure 2.2 Examples of human error while scanning dental periapical x-rays

(a) Original lower Periapical image

(b) Vertically flipped Periapical image of figure 2.2(a).

(c) Horizontally flipped Periapical image of figure 2.2(a)

(d) Rotated Periapical image of figure 2.2(a) 


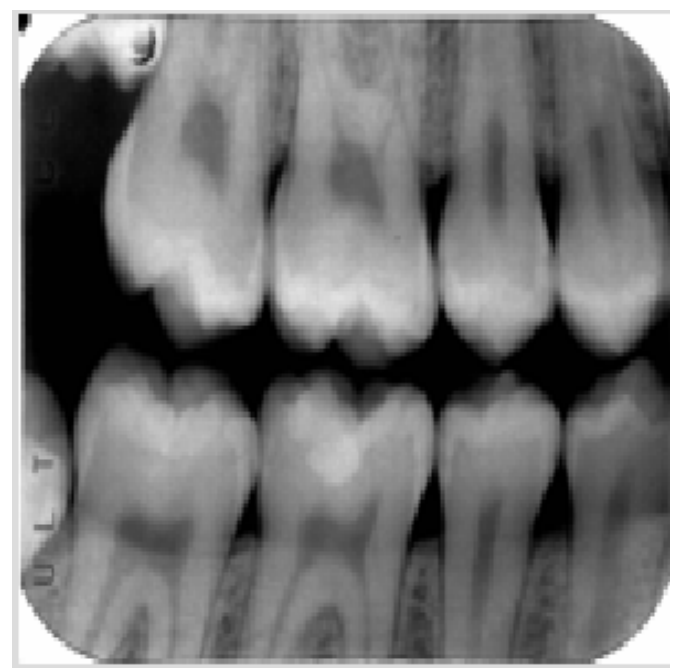

(a)

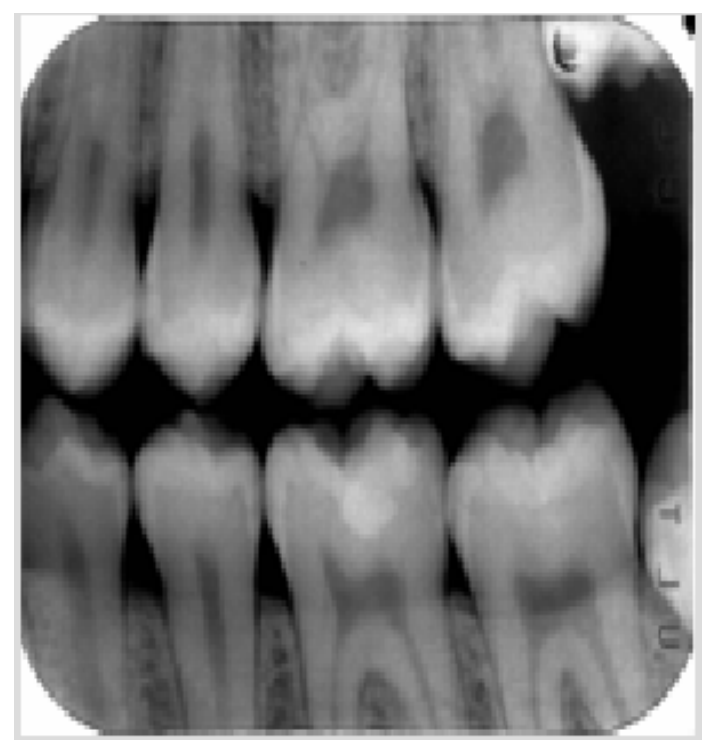

(c)

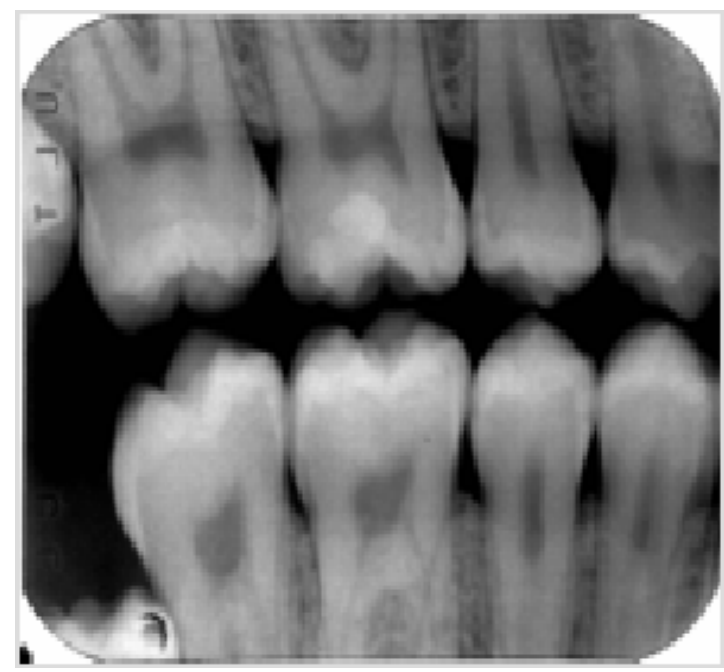

(b)

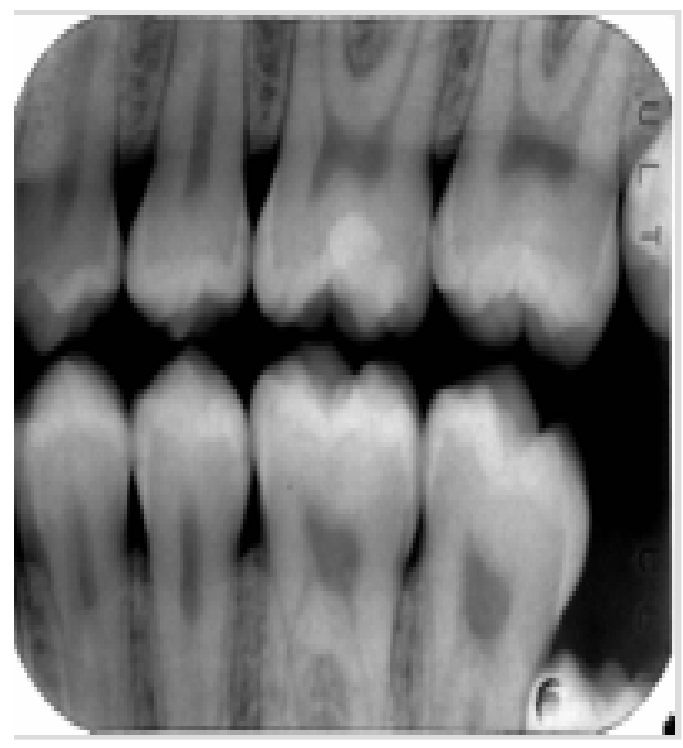

(d)

Figure 2.3 Examples of human error while scanning dental periapical x-rays

(a) Original Bitewing Image

(b) Horizontally flipped Bitewing image of figure 2.3(a).

(c) Vertically flipped Bitewing image of figure 2.3(a)

(d) Rotated Bitewing image of figure 2.3(a) 


\section{CHAPTER 3}

\section{PROBLEM STATEMENT AND RESEARCH OBJECTIVES}

In this chapter I focus on stating the problem in section 3.1 followed by our research objectives in section 3.2.

\subsection{PROBLEM STATEMENT}

In the ADIS system, there are three types of dental images; panoramic, periapical and bitewing (see Fig. 1.8). The periapical images are further sub classified into upper periapical, which shows the upper jaw (maxilla), and lower periapical, which shows the lower jaw Mandible).

Dental Image Classification is the process of classifying dental periapical images as maxilla (upper jaw) or mandible (lower jaw) or classifying dental bitewing images as flipped/rotated or un-flipped/un-rotated [Ash05]. The aim of classification for periapical images is not to detect the human errors made during scanning of the dental x-ray but is to specify whether the image is of the upper jaw or the lower jaw. Similarly the aim for classification of bitewing images is not to detect the human errors made during scanning of the x-ray but to specify whether one of the two errors; horizontal flipping or rotation is present in the image. The final information of the classification process of the dental periapical images is of the jaw bone type present in the image and the final information of the classification process of the dental bitewing images is of the presence or absence of either of the two scanning errors; the rotation or horizontal flipping errors.

The Automated Dental Identification System (ADIS) uses dental features for postmortem identification. The research frame work Automated Dental Identification System (ADIS) requires efficient image classification techniques under the preprocessing layer of image comparison component for matching the AM and PM dental images. 
Given a pair of input Anti mortem and Post mortem images, this research work aims at considering one of them as subject, the other as a reference and developing algorithms for classifying the subject and reference images.

Hence I require developing fast and robust algorithms to deal with the noisy and distorted dental images. The developed algorithms should provide reasonable performance in terms of accuracy in results and speedy generation of classification result. The image classification problem can be formulated as:

\section{PROBLEM}

(a) To determine if the given Periapical image that looks like a maxilla (upper jaw) is actually a maxilla and not a horizontally flipped mandible (lower jaw) figure 4.2.

(b) To determine if the given Periapical image that looks like a mandible (lower jaw) is actually a mandible and not a horizontally flipped maxilla.

(c) To determined if the given Bitewing image is horizontally flipped/rotated or not.

\subsection{RESEARCH OBJECTIVES}

The objectives of this research are summarized as follows:

1) Develop techniques for classification of dental Periapical and Dental bitewing images.

2) The algorithms should be robust to classify images, it should be accurate and time efficient. 


\section{CHAPTER 4}

\section{CLASSIFICATION OF DENTAL X-RAY IMAGES}

\subsection{CLASSIFICATION OF DENTAL PERIAPICAL FIMLS ON THE BASIS OF BONE DENSITY USING TEXTURE ANALYSIS}

The first technique I use for periapical images is the classification of dental periapical images as maxilla or mandible on the basis of bone density using texture analysis.

Figure 4.1 shows our method for the classification of periapical dental images. The method has three main steps. Selecting the region of interest manually, calculating the 6 statistical moments and concluding using Bayesian classification using the 6 statistical moments of texture.

The Goal of the selection of Region of Interest step is to select the bone whose texture needs to be analyzed. The bone density is of the major concern to us. Since the bone density varies over the complete bone I select three regions of interest and calculate the average of the 6 statistical moments for the three each Regions of interest.

Since the bone density is of the major concern to us, I analyze the texture of the bone. One of the simplest approaches for describing texture is to use statistical moments of the gray-level histogram of an image or region. Let $\mathrm{z}$ be a random variable denoting gray levels and let $\mathrm{p}\left(\mathrm{z}_{\mathrm{i}}\right), \mathrm{i}=0,1,2 \ldots, \mathrm{L}-1$, be the corresponding histogram, where $\mathrm{L}$ is the number of distinct gray levels. The expression for the nth moment about the mean is given by

$$
\mu_{n}=\sum_{i=0}^{L-1}\left(z_{i}-m\right)^{n} p\left(z_{i}\right)
$$

where $\mathrm{m}$ is the mean value of $\mathrm{z}$ (the average gray level): 


$$
m=\sum_{i=0}^{L-1} z_{i} p\left(z_{i}\right)
$$

Mean, Standard deviation, smoothness, skewness, uniformity and entropy, the 6 statistical moments of texture are calculated for the selected Region of Interest.

Once the 6 statistical moments are obtained, I present them to the Bayesian classification method [Duda00] to identify whether the calculated moments of the bone represent that of a maxilla or a mandible.

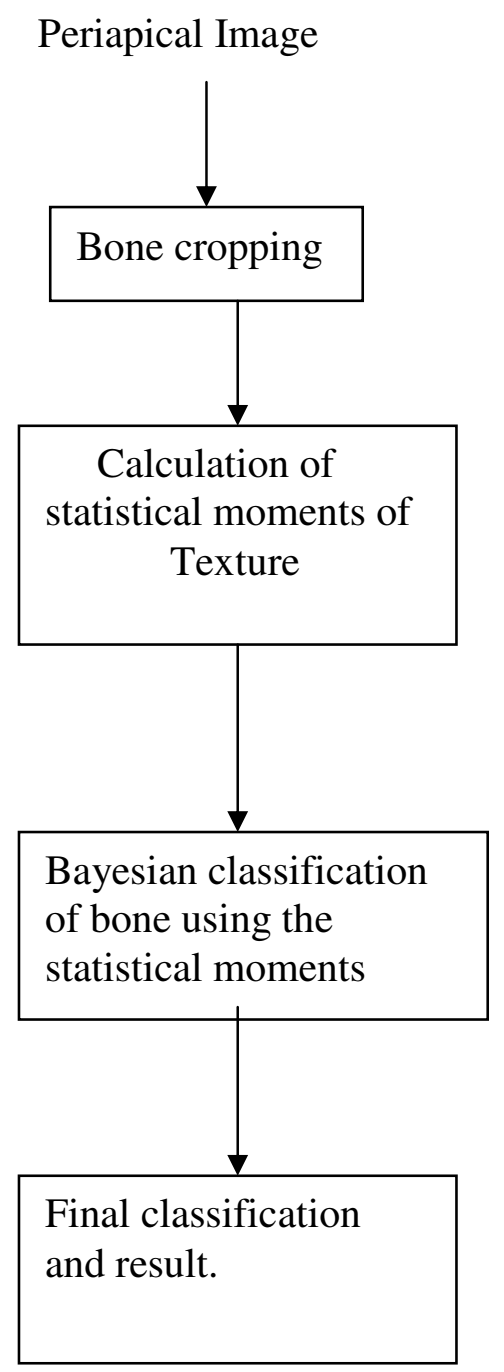

Figure 4.1 Dental Identification of dental periapical images 
Figure 4.2 shows the horizontally flipped periapical images. The image 4.2(a) appears to be of a maxilla but is actually a horizontally flipped mandible and the image 4.2(b) appears to be of a mandible but is actually a horizontally flipped maxilla. The difference in density of the bones is clearly shown in the images.

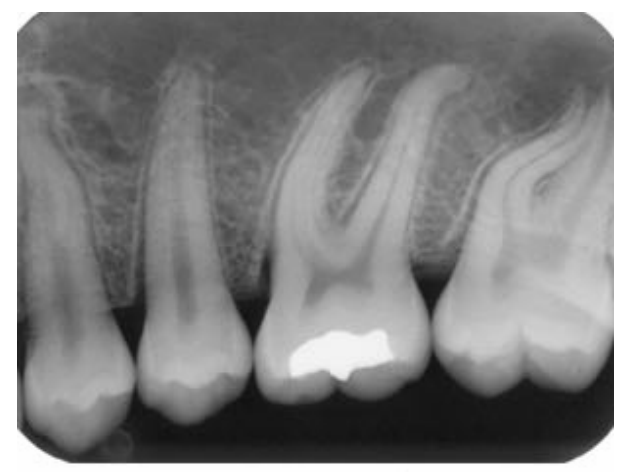

(a)

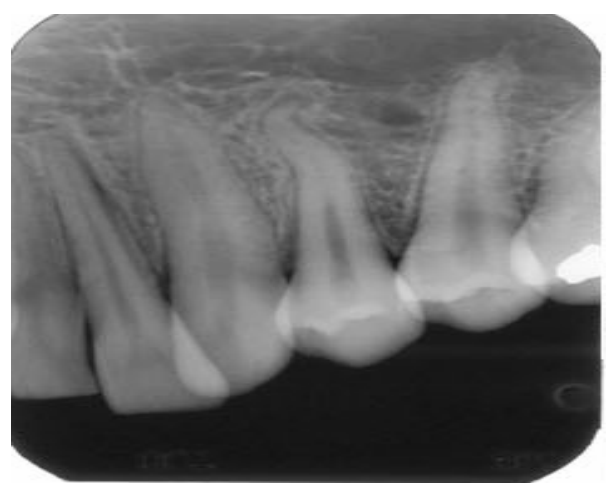

(c)

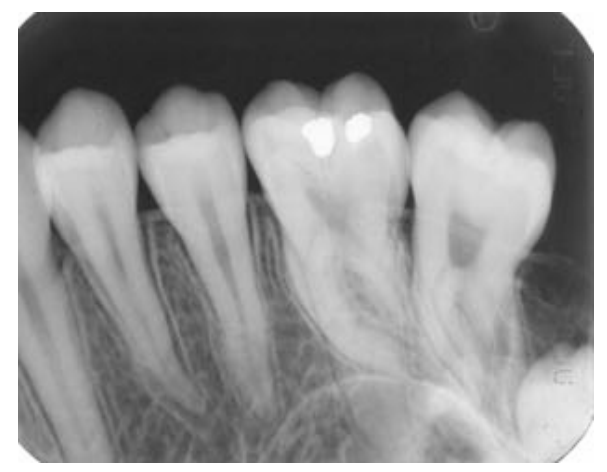

(b)

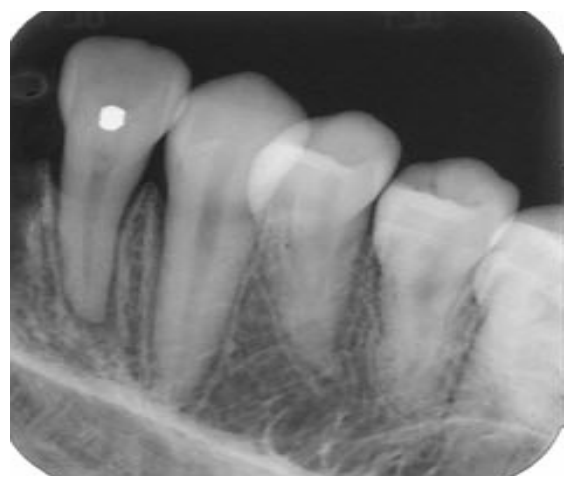

(d)

Figure 4.2 Arrangement of teeth in flipped dental Periapical images

(a) Horizontally flipped Periapical image of a mandible

(b) Horizontally flipped Periapical image of a maxilla.

(c) Horizontally flipped Periapical image of a mandible

(d) Horizontally flipped Periapical image of a maxilla 


\subsubsection{STATISTICAL MOMENTS}

Observing the bone density using texture analysis is considered as a powerful method [Southard96]. It has useful properties including: simplicity of implementation and efficiency on speed. Less density in the bone means that there is more randomness in the pixels of the image [Ash05]; where as high density in the bone suggests less randomness in the pixels of the image. Our sixth statistical moment of texture, entropy, gives us a measure of the randomness in an image. A bone which is highly dense (mandible) would be more uniform where as a bone that is low on density (maxilla) will show less uniformity. Our fifth statistical moment of texture, uniformity, gives us a measure of the density of the bone.

Recall the statistical moments [Gonza02] given above in Equation. 1. Note from this Equation that $\mu 0=1$ and $\mu_{1}=0$. The second moment [the variance $\left.\sigma^{2}(z)=\mu_{2}(z)\right]$ is of particular importance in texture description. It is a measure of gray- level contrast that can be used to established descriptors of relative smoothness. For example, the measure

$$
\mathrm{R}=1-\left(1 /\left(1+\sigma^{2}(\mathrm{z})\right)\right)
$$

is 0 for areas of constant intensity (the variance is zero there) and approaches 1 for large values of $\sigma^{2}(\mathrm{z})$, Because variance values tend to be large for gray-scale images with values, for example, in the range 0 to 255 , it is a good idea to normalize the variance to the interval $[0,1]$ for use in Equation. 3. This is done simply by dividing $\sigma^{2}(\mathrm{z})$ by $(\mathrm{L}-1)^{2}$ in Equation. 3. The standard deviation $\sigma(z)$, also is used frequently as a measure of texture because values of the standard tend to be more intuitive to many people.

The third moment,

$$
\mu_{3}=\sum_{i=0}^{L-1}\left(z_{i}-m\right)^{3} p\left(z_{i}\right)
$$

is a measure of the skewness of the histogram while the fourth moment is the measure of its relative flatness. The fifth and higher moments are not is easily related to histogram 
shape, but they do provide further quantitative discrimination of texture content. Some useful additional texture measures based on histograms include a measure of "uniformity," given by

$$
U=\sum_{i=0}^{L-1} p^{2}\left(z_{i}\right),
$$

and an average entropy measure, from basic information theory is defined as

$$
e=-\sum_{i=0}^{L-1} p\left(z_{i}\right) \log _{2} p\left(z_{i}\right)
$$

Because the $p$ has values in the range $[0,1]$ and their sum equals 1 , measure $U$ is maximum for an image in which all the gray levels are equal (maximally uniform), and decreases from there. Entropy is a measure of variability and is 0 for a constant image.

\subsubsection{FINAL CLASSIFICATION}

During classification, I need to deal with difficulties arising from the bone loss which affects the density of the bone. There are several factors affecting bone density; hormones like estrogen, progesterone directly affect the bone density therefore there is rapid bone loss in post menopausal women, other than that diabetes or nutritional deficiencies of different minerals or vitamins also affects the bone density [Ash05]. Bone cancer, consumption of alcohol, smoking and some hormones like the thyroid hormone also affects the bone density. In addition some periapical images do not show adequate bone for analysis. To resolve these problems and to identify the bone correctly I crop three regions of interest of the bone for analysis and take the mean of statistical moments of the three regions. 
If I assume that the bone under analysis has not under gone any bone loss due to the factors discussed above, then I can assume that the maxilla will display a low amount of density and the mandible will display a high amount of density. Using this information after the calculation of the 6 statistical moments of texture of the bone, the Bayesian classification classifies the dental periapical image as maxilla (upper jaw) or mandible (lower jaw).

\subsection{CLASSIFICATION OF DENTAL PERIAIPCAL FILMS USING THE CROWN CURVE}

The second technique I use for periapical images is the automated approach for the classification of dental periapical images as maxilla or mandible. This technique makes use of the fact that the crowns of the teeth in the upper jaw (maxilla) show a rising curve from the center to the right and the left. Similarly the crowns of the teeth in the lower jaw (mandible) show a rising curve from the center to the right and the left figure 4.3(a) [19]. If figure 4.3(b) is flipped horizontally then the crowns of the teeth in the upper jaw (maxilla) will show a falling curve from the center to the right and the left and the teeth in the lower jaw (mandible) will show a rising curve from the center to the right and the left figure 4.4. Efficiently determining the shape of the crown curve, I can classify the periapical images as maxillae or mandibles.

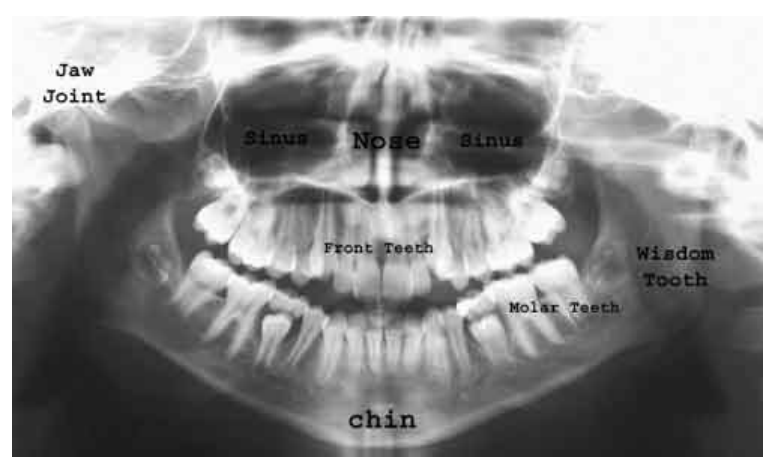

(a)

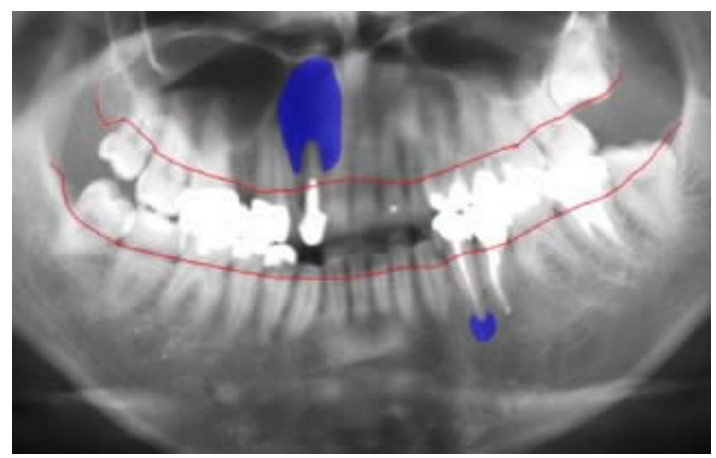

(b)

Figure 4.3 Arrangement of teeth in dental Panoramic images.

(a) Labeled panoramic Image. 
(b) The red lines show the rising and the falling curves of the crowns.

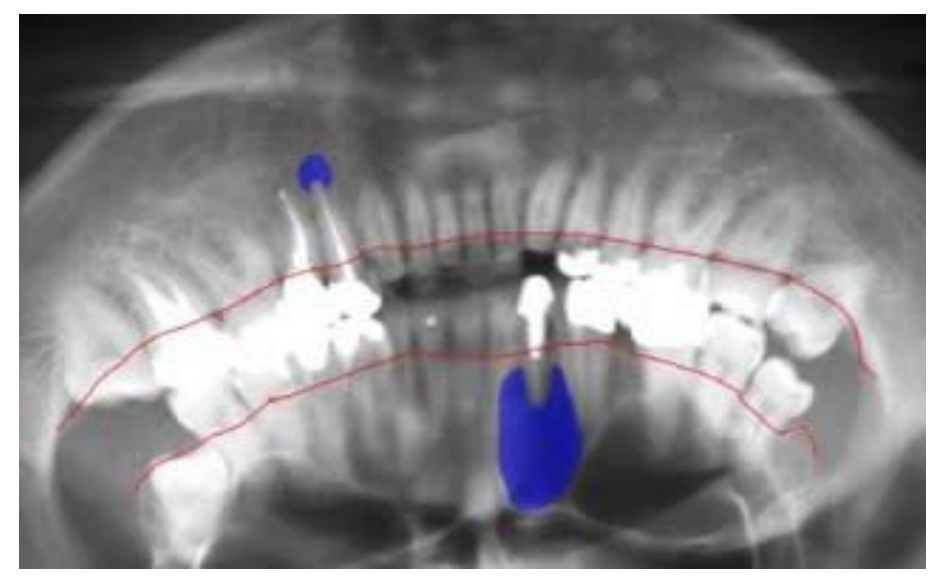

Figure 4.4. Horizontally flipped image of figure 4.3(b).

Unlike our previous approach I have an automated approach to classify periapical images. Figure 4.5 shows our method for the classification of periapical dental images. The method has four main steps; Check what the image looks like (maxilla or a mandible), convert to binary, develop a curve showing the crowns of teeth and then conclude on the basis of the curve of the crowns. 


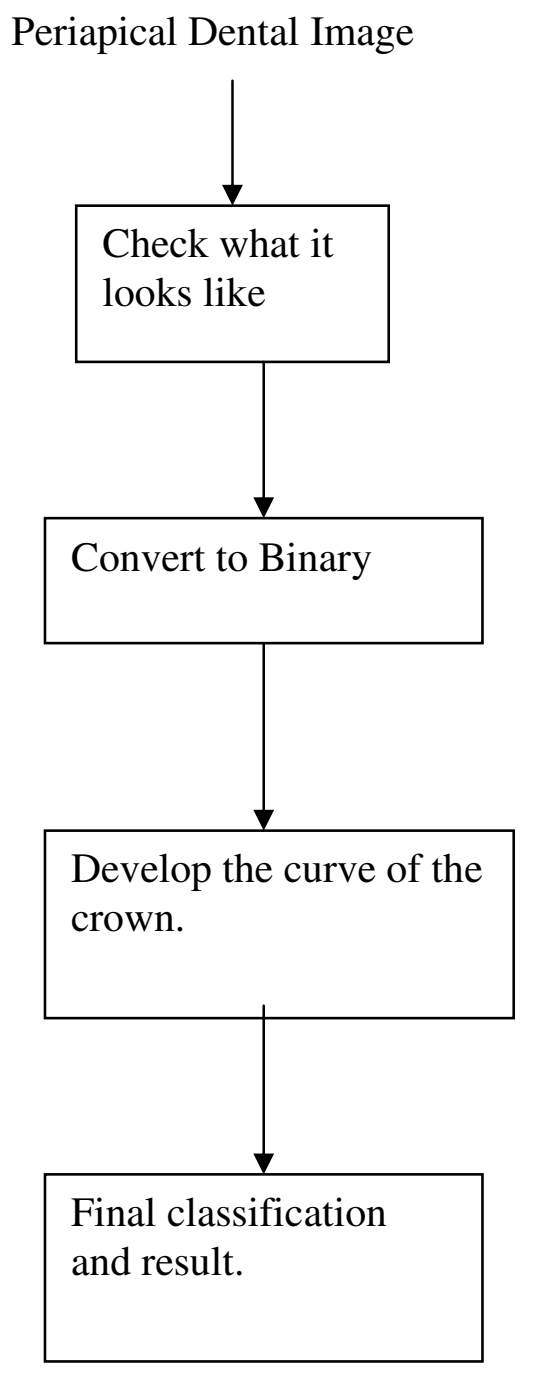

Figure 4.5 Dental Classification of periapical images 


\subsubsection{WHAT THE IMAGE LOOKS LIKE}

A dental periapical image may look like maxilla but it might actually be a horizontally flipped mandible, and similarly a dental periapical image may look like mandible but it might actually be horizontally flipped maxilla, figure 4.6. The goal to check whether the given dental periapical image looks like a mandible or a maxilla, is to determine whether to flip the image horizontally or not. Since our algorithm analyzes the curve of the crown from the top as shown in figure 4.7, a dental periapical image that looks like a maxilla needs to be flipped horizontally in order to be analyzed by looking at the curve of the crown. On the other hand an image that looks like a mandible is perfectly fine for our analysis and does not need to be flipped.

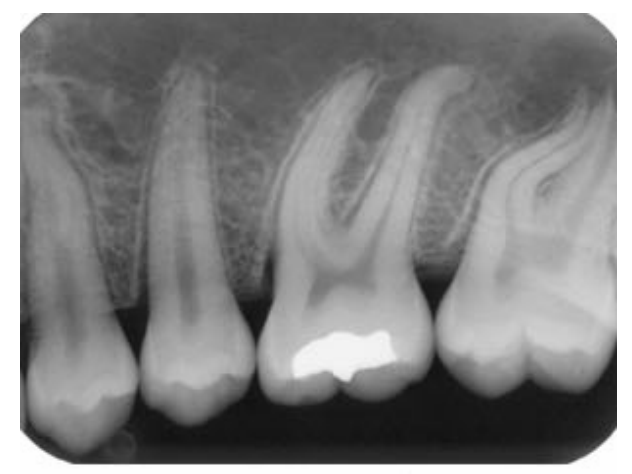

(a)

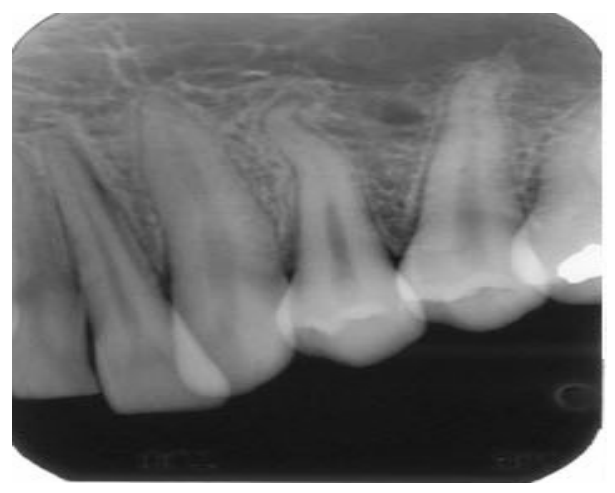

(c)

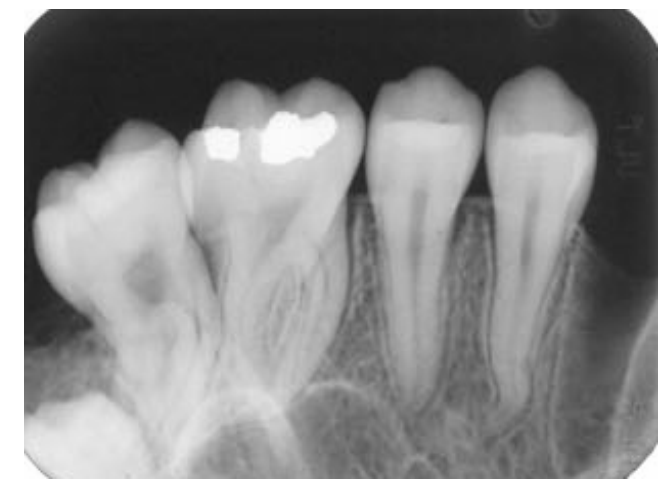

(b)

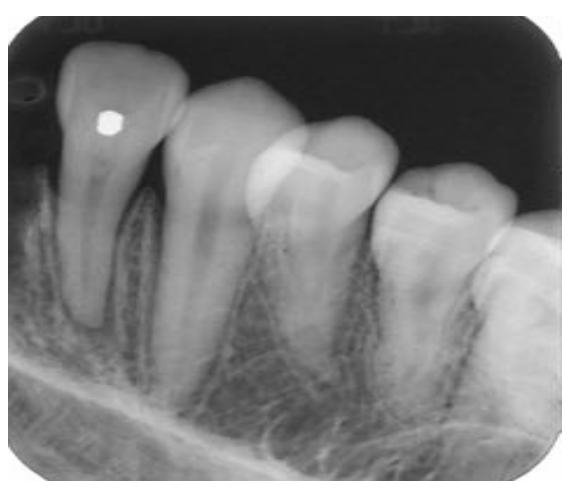

(d)

Figure 4.6 Arrangement of teeth in flipped dental Periapical images 
(a) Horizontally flipped Periapical image of a mandible

(b) Horizontally flipped Periapical image of a maxilla.

(c) Horizontally flipped Periapical image of a mandible

(d) Horizontally flipped Periapical image of a maxilla

\section{Analyze crown curve from the top}

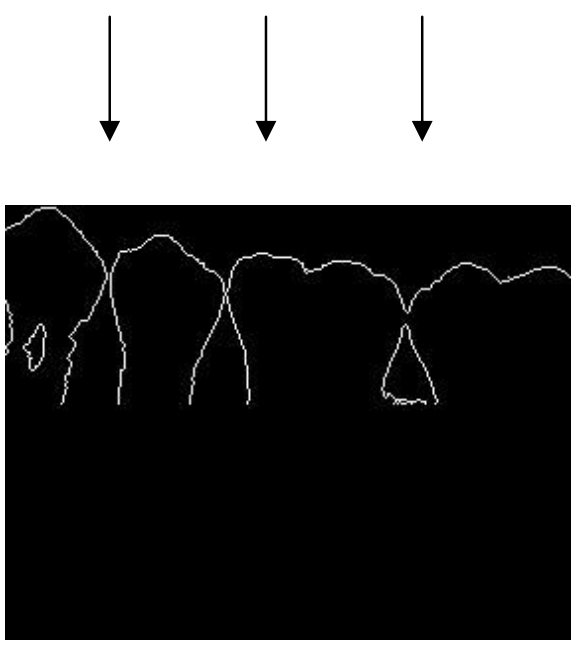

(a)

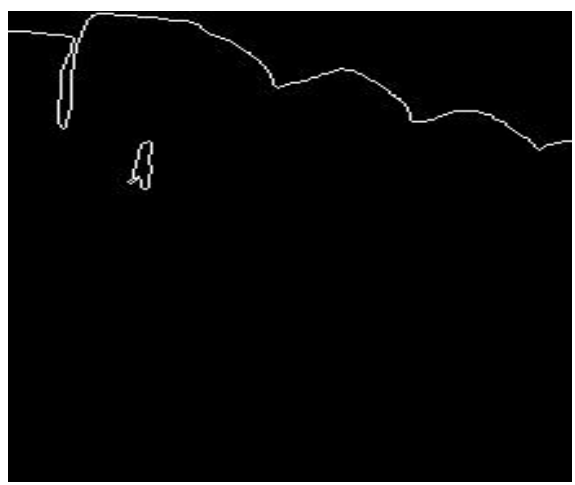

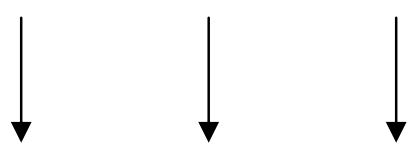

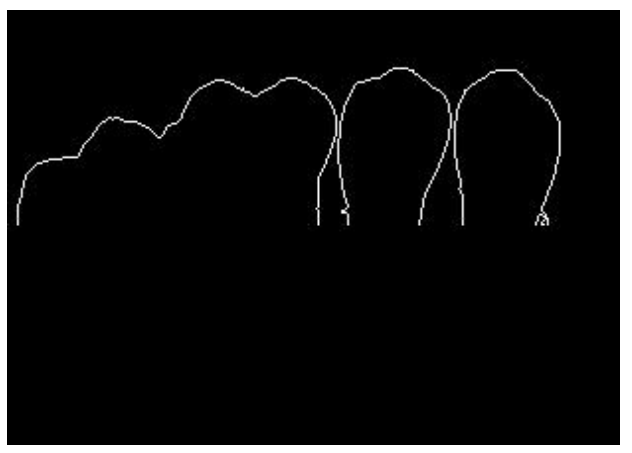

(b)

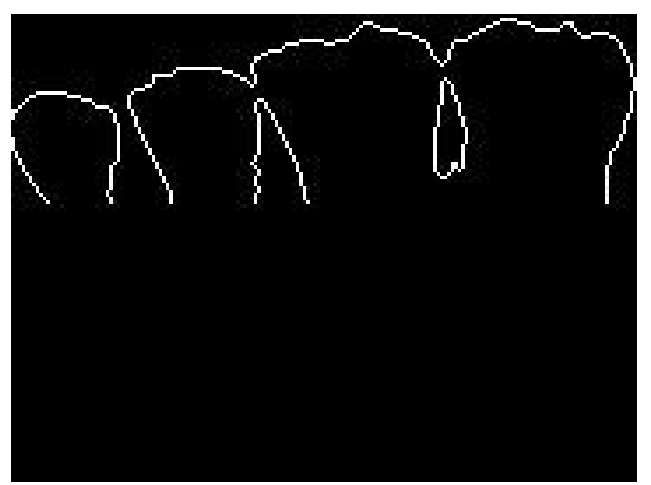


(c)

Figure 4.7 Arrangement of crown curve.

(a) The crown curve of the teeth in figure 4.6(a)

(b) The crown curve of the teeth in figure 4.6(b).

(c) The crown curve of the teeth in figure 4.6(c)

(d) The crown curve of the teeth in figure 4.6(d)

\subsubsection{CONVER THE IMAGE TO BINARY:}

After determining whether to flip the image horizontally, I convert the image into a binary image as shown in figure 4.8 .

$$
m= \begin{cases}1 & Z_{i j} \geq t h \\ 0 & Z_{i j}>t h\end{cases}
$$

Figure 10 shows the image in figure 8 after being converted into a binary image. The small structures displayed in figure need to be removed and only the edges of the crowns need to be present in the image figure 6 . I use a morphological function to remove small structures in our binary image.

$$
E(A, B)=A \oplus(-B)=\bigcap_{\beta \in B}(A-\beta)
$$




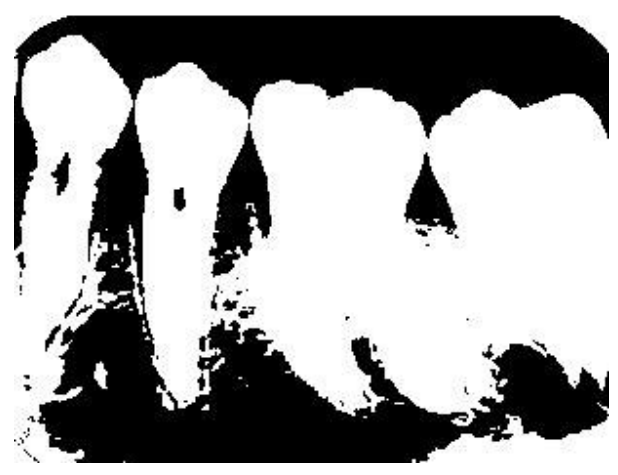

(a)

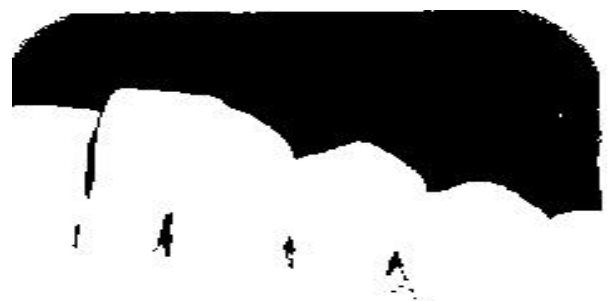

(c)

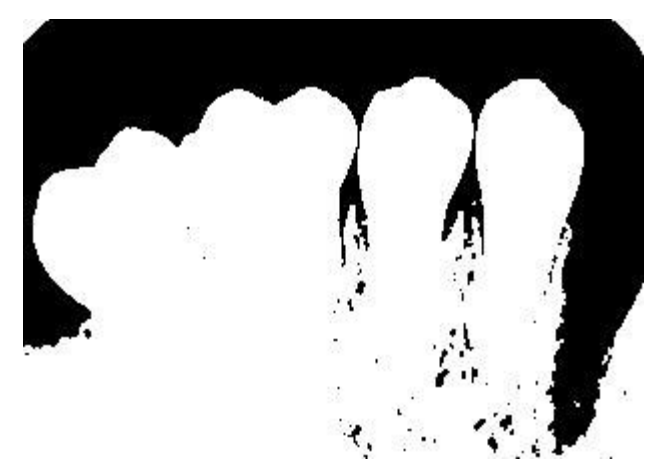

(b)

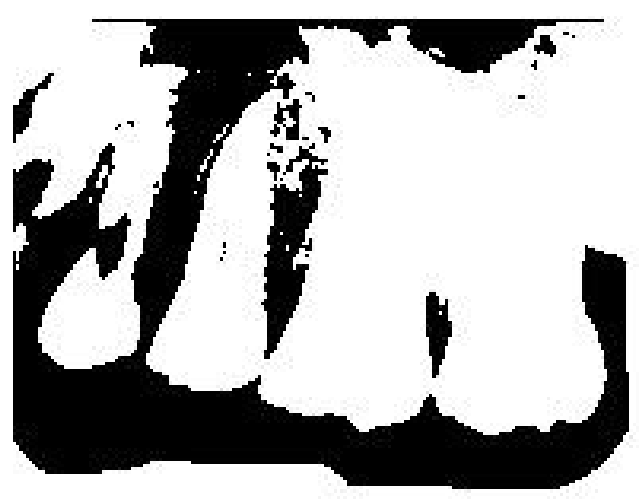

(d)

Figure 4.8 Binary images of the images in figure 4.6.

(a) The binary image of figure 4.6(a).

(b) The binary image of figure 4.6(b).

(c) The binary image of figure 4.6(c).

(d) The binary image of figure 4.6(d).

\subsubsection{HANDLE THE DENTAL HOLDER IN PERIAPICAL FILMS}

In most of the dental periapical images I face a problem of the X-ray holder which is shown by the arrow heads in figure 4.9 on the bottom right corner and in figure 4.10 in the bottom left corner. The holder displays a structure in the binary image which causes hindrance to the detection of the crown curve. I remove the holder from the binary image by using a summing function which sums up the values of the pixels along a single row. 


$$
m=\sum_{j=0}^{M} Z_{i j}
$$

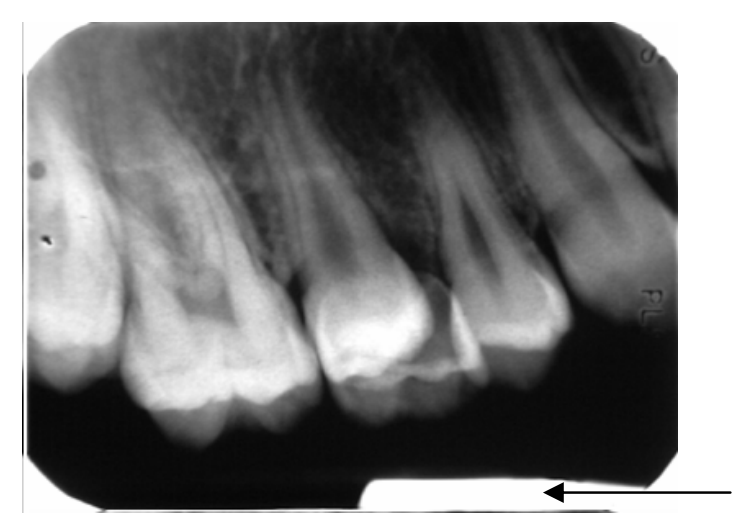

Figure 4.9 A dental periapical image exhibiting the xray holder in the bottom right.

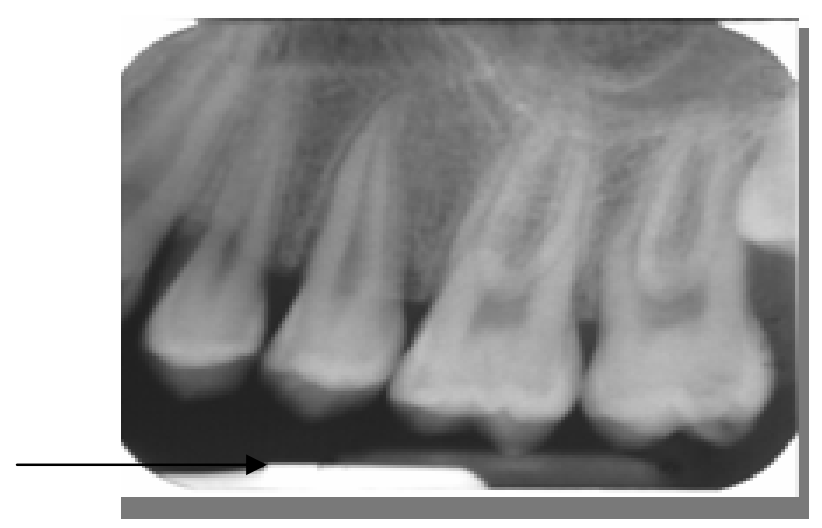

Figure 4.10 A dental periapical image exhibiting the xray holder in the bottom left.

\subsubsection{ANALYZING THE CROWN CURVE}

The algorithm checks the curve of the crowns from the top as shown in figure 4.7. If I have a falling curve in a concave manner as shown in figure 4.11(b) and in figure 4.11(d), I conclude that the periapical image is of a maxilla and if I have a rising curve in a convex manner as shown in figure 4.11(a) and in figure 4.11(c), I conclude that the periapical image is of a mandible. 


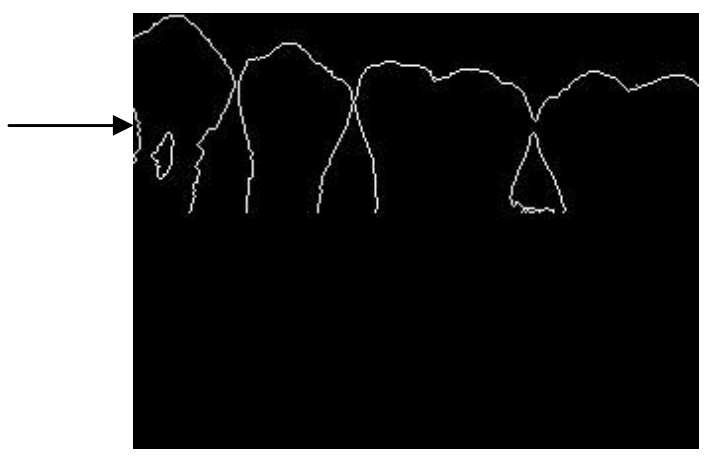

(a)

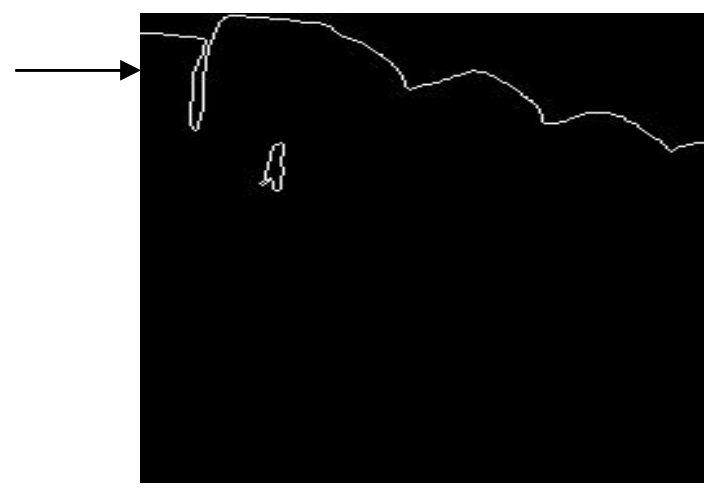

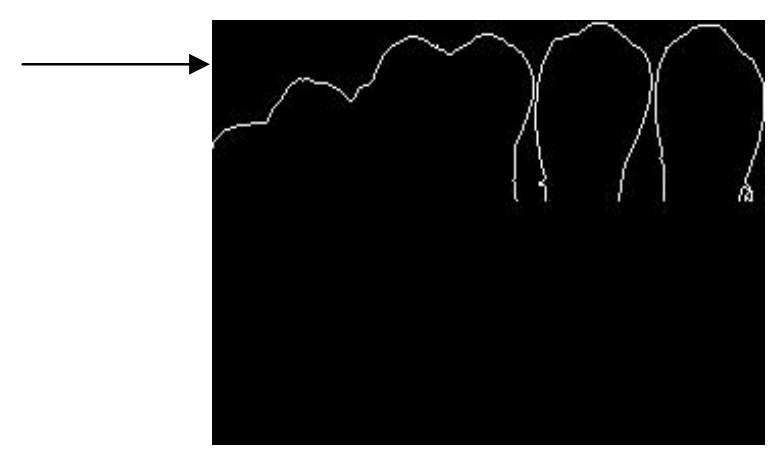

(b)

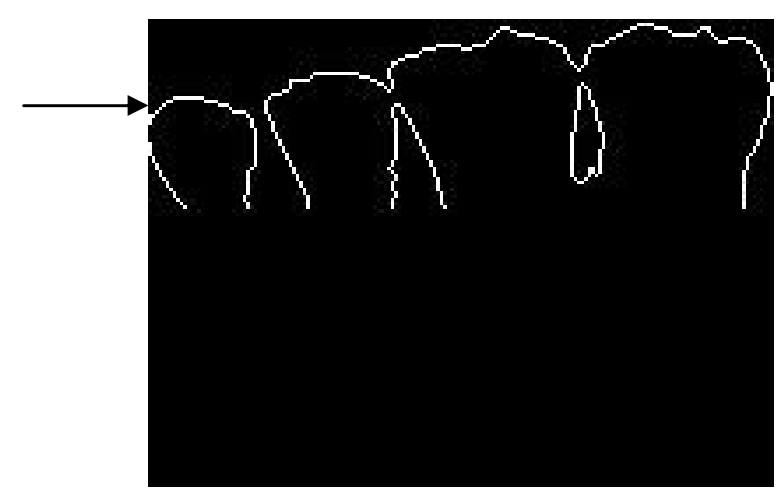

Figure 4.11 Arrangement of crown curve dental Periapical images of figure 4.6.

(a) The arrow points towards the rising curve of the crowns displayed only in mandibles.

(b) The arrow points towards the falling curve of the crowns displayed only in maxilla.

(c) The arrow points towards the rising curve of the crowns displayed only in mandibles.

(d) The arrow points towards the rising curve of the crowns displayed only in maxilla. 


\subsection{CLASSIFICATION OF DENTAL BITEWING IMAGES}

Our technique for the classification of dental bitewing images is an automated one which makes use of the fact that the maxillary molars (the molars in the upper jaw) have three roots and the mandibular molars (the molars in the lower jaw) have tow roots figure 4.12.

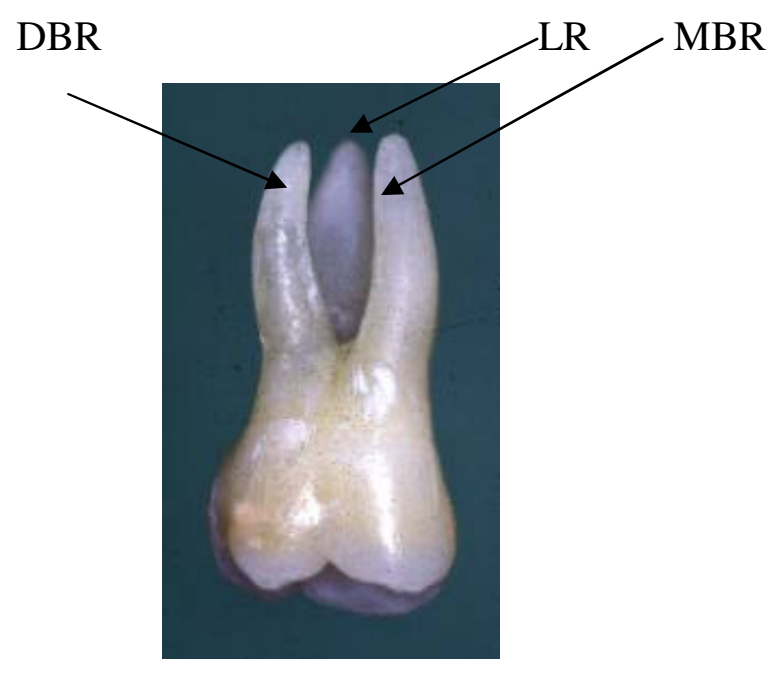

(a)

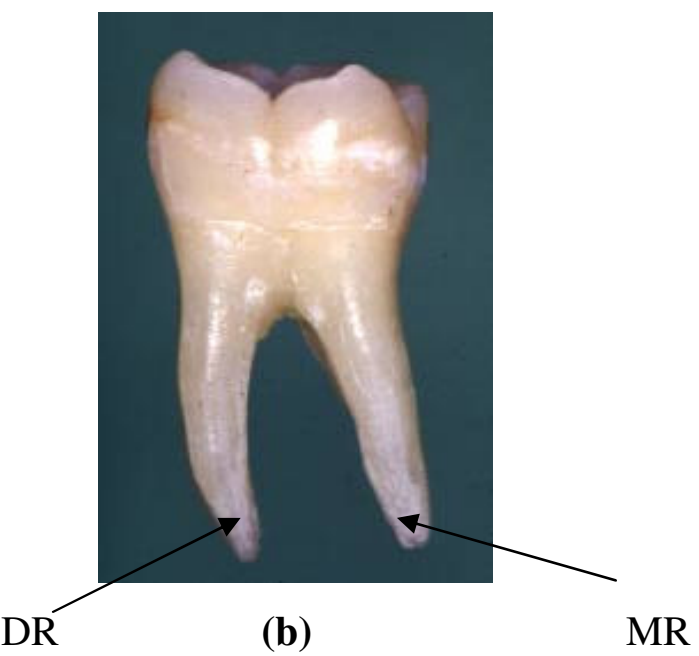

Figure 4.12 Labeled maxillary and madibular molars.

(a) Maxillary Molar, buccal Aspect. DBR, Distobuccal root; LR, Lingual root; MBR, mesiobuccal root [Ash05].

(b) Mandibular Molar, buccal Aspect. MR, Mesial root; DR, Distal root [Ash05].

The mean value around the root area of the mandibular molar teeth is lower than the mean value around the root area of the maxillary molar teeth. As shown in figure 4.13 the area around the molars in the upper jaw exhibits a higher mean value because of the presence of the third root which is absent in the lower molars. 


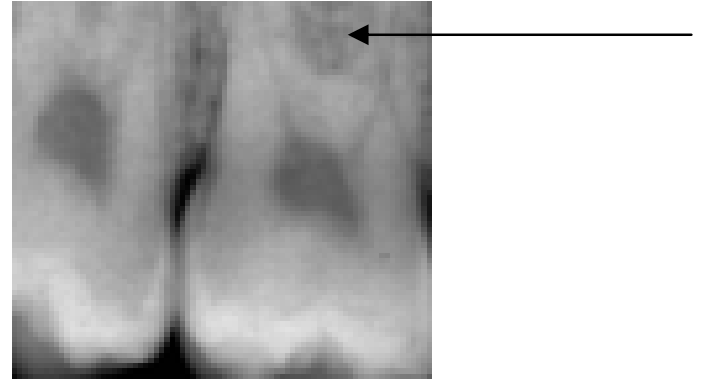

(a)

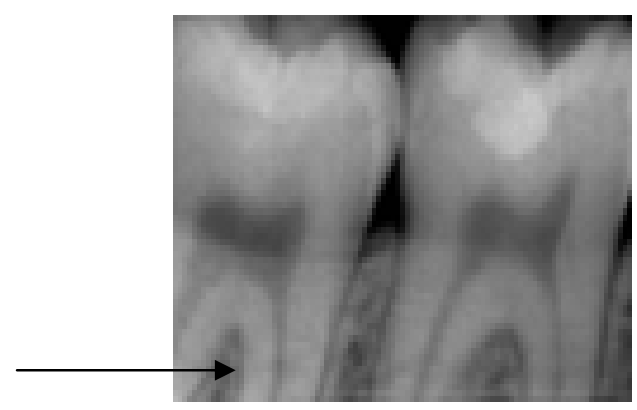

(b)

Figure 4.13 Arrangement of molars in dental Bitewing images.

(a) The arrow points towards the bone area which has a higher mean because of the presence of the third root.

(b) The arrow points towards the bone area which has a lower mean because of the absence of the third root.

Our classification method for the bitewing images has three main steps; Crop the regions around the roots of the upper and the lower molars, calculate the mean for both the upper and the lower regions, classify on the basis of the means of the bone regions.

\subsubsection{Cropping:}

The Molars in the bitewing images usually appear in the center region of the upper and lower bone. Hence I use an automated cropping method which crops the center regions from the upper and the lower root areas of the jaws.

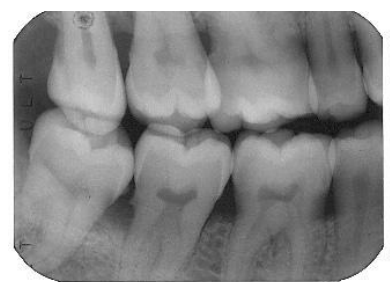

Right

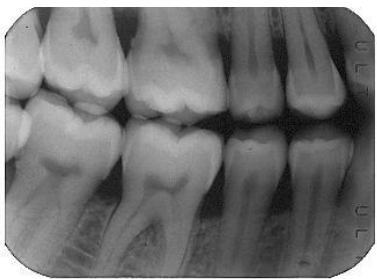

Antemortem

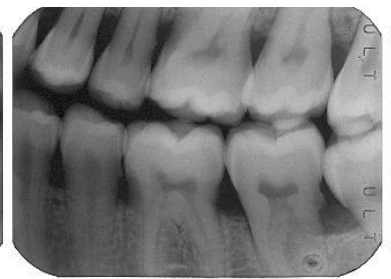

9/23/95

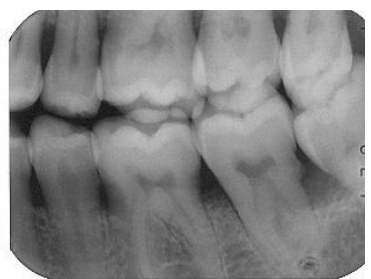

Left

Figure 4.14 Bitewing images shows the molars around the center of the film. 


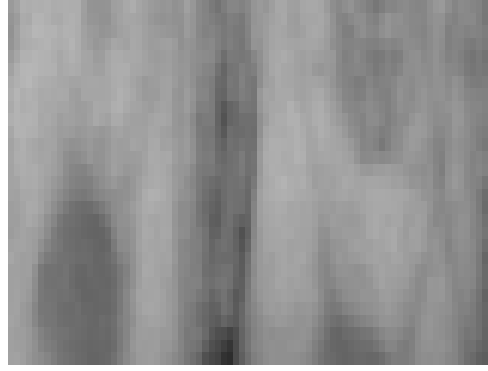

(a)

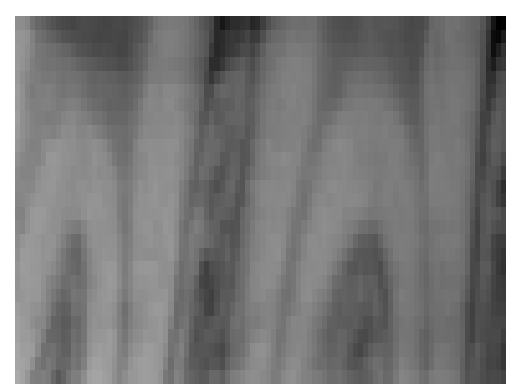

(b)

Figure 4.15 Root regions of the upper and the lower molars in dental Bitewing images.

(a) The root region around the upper molars displaying a high mean value.

(b) The root region around the lower molars displaying a low mean value.

\subsubsection{Calculating the means:}

Using equation 2, I calculate the mean value of $\mathrm{z}$ (the average gray level) of the cropped regions. The mean value for figure 4.15 (a) is 142.6945 and the mean value for figure 4.15 (b) is 113.2407 showing that the upper region has a higher mean than the lower one.

\subsubsection{Concluding on the basis of the calculated means:}

I analyze the mean values of the upper and the lower cropped regions and classify the bitewing image. If the lower region displays a higher mean as compared to the upper region then the bitewing image is as a horizontally flipped or rotated image, otherwise it is an un-flipped or un-rotated image. 


\section{CHAPTER 5}

\section{RESULTS AND ANALYSIS}

\section{EXPERIMENTS AND RESULTS}

The dental radiographs used for the classification of dental periapical images were extracted from the digitized dental images database provided by the CJIS [CJISO0] [CJIS02]. I make a test set of a 190 periapical images with different qualities to test and train the system for the texture analysis technique for classification of dental periapical images. The same tests set of 190 images was used in the crown curve detection technique for the classification of dental periapical images.

Out of the 190 periapical images 95 are maxilla and 95 are mandible images. All films in the test set contain 3-8 teeth per film. Testing results of the first technique are shown in figure 6.1 and Table. 6.1 and the testing results of the second technique are shown in Table. 6.2. In our experiment for the classification of dental bitewing images, I use a test set of 495 bitewing images which are accurately cropped [Li06] from their respective records and vary on quality [CJIS00] [CJIS02]. The results for the classification of dental bitewing images are shown in table 6.3.

Figure 6.1 shows the results from the Bayesian classification. The figure shows the true state of nature, the assigned class and the percentage of samples. The blue bars in the figure show the percentage of mandibles classified as correctly and the red buildings in the figure show the maxillas classified correctly. The taller blue bar shows that the Bayesian classifier assigns 78 out of 95 mandible images (lower jaw images) as lower jaw images which corresponds to the true state of nature. The shorter blue building shows that the Bayesian classifier assigns 17 out of 95 mandible images (lower jaw images) as upper jaw images which does not correspond to the true state of nature. Similarly the taller red building shows that the Bayesian classifier assigns 62 out of 95 maxilla images 
(upper jaw images) as upper jaw images, which corresponds to the true state of nature. The shorter blue building shows that the Bayesian classifier assigns 33 out of 95 maxilla images (upper jaw images) as lower jaw images which does not correspond to the true state of nature. Table 6.1 shows the number and percentage of the correctly and incorrectly classified images according to the Bayesian classifier explained above.

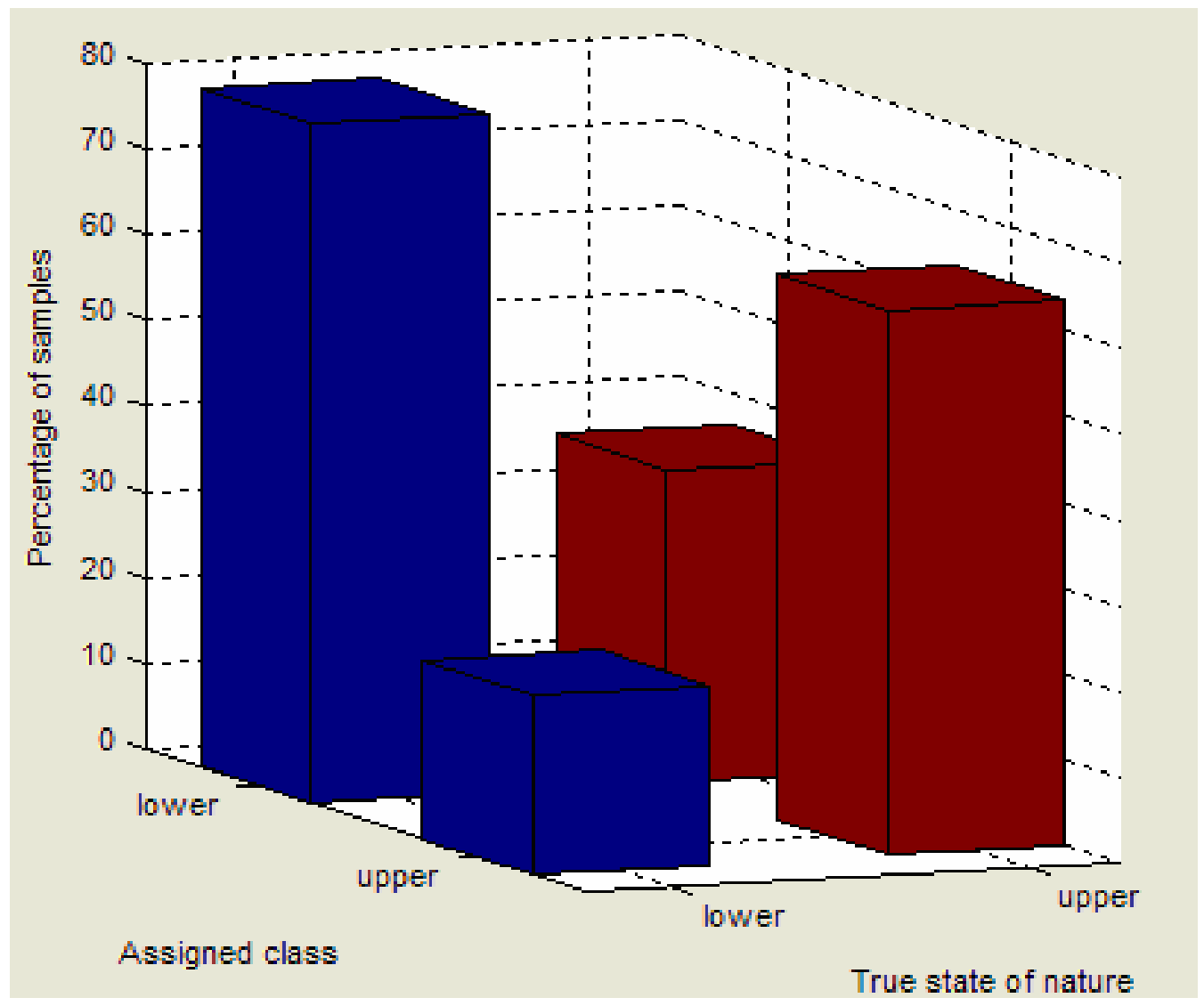

Figure 6.1 Results after Bayesian Classification

Table 6.2 shows the classification of dental periapical images on the basis of crown curve detection. The second row of Table 6.2 shows that the system classifies 80 out of 95 
maxilla images correctly as maxilla or upper jaw images while classifying 15 out of 95 maxilla images incorrectly as mandible or lower jaw images. The third row of Table 6.2 shows that the system classifies 76 out of 95 mandible images correctly as mandible or lower jaw images while classifying 19 out of 95 mandible images incorrectly as maxilla or upper jaw images. The classified percentages are also shown in table 6.2.

In My experiment for the classification of dental bitewing images, I use a test set of 495 bitewing images which are accurately cropped [Li06] from their respective records and vary in quality. The dental bitewing images were extracted from the digitized dental images database provided by the CJIS [CJIS00] [CJIS02]. The results for the classification of dental bitewing images are shown in table 6.3. In out test set of 495 bitewing images I have 245 horizontally flipped images and the rest 250 are un-flipped. The second row of Table 6.3 shows that the system classifies 194 out of 250 un-flipped images correctly as un-flipped images while classifying 56 out of 250 un-flipped images incorrectly as flipped images. The third row of Table 6.3 shows that the system classifies 200 out of 245 horizontally flipped images correctly as flipped images while classifying 45 out of 245 flipped images incorrectly as un-flipped images. The classified percentages are also shown in table 6.3. 


\begin{tabular}{|l|l|l|l|l|l|}
\hline & Total & $\begin{array}{l}\text { Correctly } \\
\text { Classified }\end{array}$ & $\begin{array}{l}\text { In-correctly } \\
\text { Classified }\end{array}$ & $\begin{array}{l}\text { \%age } \\
\text { Correctly } \\
\text { Classified }\end{array}$ & $\begin{array}{l}\text { \%age In- } \\
\text { Correctly } \\
\text { Classified }\end{array}$ \\
\hline Maxilla & 95 & 62 & 33 & $65 \%$ & $35 \%$ \\
\hline Mandible & 95 & 78 & 17 & $82 \%$ & $18 \%$ \\
\hline Combined & 190 & 140 & 50 & $73 \%$ & $27 \%$ \\
\hline
\end{tabular}

Table 6.1. Results of Classification of dental periapical images on the basis of bone density using texture analysis.

\begin{tabular}{|l|l|l|l|l|l|}
\hline & Total & $\begin{array}{l}\text { Correctly } \\
\text { Classified }\end{array}$ & $\begin{array}{l}\text { In-correctly } \\
\text { Classified }\end{array}$ & $\begin{array}{l}\text { \%age } \\
\text { Correctly } \\
\text { Classified }\end{array}$ & $\begin{array}{l}\text { \%age In- } \\
\text { Correctly } \\
\text { Classified }\end{array}$ \\
\hline Maxilla & 95 & 80 & 15 & $84 \%$ & $16 \%$ \\
\hline Mandible & 95 & 76 & 19 & $80 \%$ & $20 \%$ \\
\hline Combined & 190 & 156 & 34 & $82 \%$ & $18 \%$ \\
\hline
\end{tabular}

Table 6.2. Results of Classification of dental periapical images using crown curve.

\begin{tabular}{|l|l|l|l|l|l|}
\hline & Total & $\begin{array}{l}\text { Correctly } \\
\text { Classified }\end{array}$ & $\begin{array}{l}\text { In-correctly } \\
\text { Classified }\end{array}$ & $\begin{array}{l}\text { \%age } \\
\text { Correctly } \\
\text { Classified }\end{array}$ & $\begin{array}{l}\text { \%age In- } \\
\text { Correctly } \\
\text { Classified }\end{array}$ \\
\hline Un-flipped & 250 & 194 & 56 & $77.60 \%$ & $22.40 \%$ \\
\hline Flipped & 245 & 200 & 45 & $81.63 \%$ & $18.37 \%$ \\
\hline Combined & 495 & 394 & 101 & $79.61 \%$ & $20.39 \%$ \\
\hline
\end{tabular}

Table 6.3 Results of classification of dental bitewing images. 


\section{CHAPTER 6}

\section{CONCLUSIONS}

In this work I introduce three techniques for classification of dental images. Out of the three techniques, two are useful for dental periapical images and one is useful for the bitewing dental images. My first technique for the dental periapical images is for robust classification of the jaw bone in periapical images using texture analysis. After calculating the statistical moments of the texture, the Bayesian classification produces a result by using the statistical moments of texture. My experiment shows that this method identifies the lower jaw bone (mandible) in the periapical dental images with a higher accuracy as compared to my second method for the classification of dental periapical images. The over all failure rate for the first technique is $27 \%$ table 1 .

My second technique for the dental periapical images is an automated dental image classification that uses the crowns curve for classification. The proposed algorithm includes (i)Checking what the image looks like(ii) Converting the images to binary (iii) developing a curve of the crowns in the binary image by using the connectivity of the pixels.(iv) Concluding on the basis of crown curve.

Testing results of the second approach shows that the failure rate of My approach is $18 \%$ table 2. Comparing these results with the ones obtained for the first approach in table 1, My second approach exhibits a lower failure rate and has the advantage of being automated.

My technique for the dental bitewing images is an automated classification technique that uses the mean values around the root areas of the molars to carry out the classification. After successfully cropping the root regions around the molars I calculate the mean by equation 2 and classify on the basis of the mean of the upper and the lower regions.

Testing results of this approach shows that the failure rate of my approach when the images are horizontally flipped or rotated is $18.37 \%$ table 3 . The over all failure rate is 
$20.39 \%$ table 3 . The sample test of 495 bitewing images was tested in $\sim 17$ seconds which shows the time efficiency of my approach. 


\section{CHAPTER 7}

\section{FUTURE WORK}

In this chapter I discuss the future work for the classification of dental periapical images as maxilla or mandible and classification of dental bitewing images as flipped/rotated or un-flipped/un-rotated images.

Image classification plays a vital role in most Forensic identification systems. Since research in various new technologies in Biometrics and Forensic Science is fast escalating, I emphasize on a wide range of improvements for classification techniques.

Since no known work had been done in this field there is a lot of scope for improvements in the proposed dental image classification algorithm.

The classification technique used for the classification of dental periapical images as maxilla or mandible on the basis of bone density has a cropping step which is carried out manually. The bone regions are cropped and the six moments of texture are calculated for the cropped regions. Since I am building an automated system, I are left to explore the automation of the cropping of the bone region automatically. In this technique I have used the first order statistical moments of texture which are mean, standard deviation, smoothness, skewness, uniformity and entropy. Second and third order gray level statistics can be used to explore the enhancement of the results [Southard96].

My second approach for the classification of dental periapical images as maxilla or mandible is based on using the crown curve and is automated. Here, I propose enhancements of my classification technique that provide scope for future implementation. As discussed in the previous chapters, I have adopted edges as features for obtaining the crown curve figure 4.11, and adopted Sobel Edge detection technique. Better edge detection techniques can be investigated that provide clear edges even at lower resolution of the image. Noise present in images is another factor that can be considered for future work on edge detection methods. Another aspect to be investigated is the use of the bone curve rather than the crown curve. To investigate this technique, I 
need efficient contour extraction methods in which the contours of the teeth are removed from the image. If I can efficiently remove the teeth contours from an image and be left with the bone, then I can use the curve displayed by the bone in a similar way as I are using the crown curve to classify the image as a maxilla or a mandible.

The classification technique used for the classification of dental bitewing images as horizontally flipped or unflipped is carried out in an automated manner by using the mean of the regions around the roots of the molar teeth in the upper and the lower jaw. Here, I propose some issues of my classification technique that provide scope for future implementation. As discussed in the previous chapters, I have a method to check the mean value around roots of the molar teeth in the upper and the lower jaw by cropping those regions. The adopted method crops an estimated region around the molar roots and calculates the mean. Better cropping techniques can be investigated that provide the exact areas around the roots of the molars. On the other hand by using efficient segmentation and teeth labeling methods I can investigate the classification of bitewing images. The labels can provide us the information about the molars and by segmenting the molars and analyzing the mean value of the segments, I can have another technique for classification of the bitewing images. Another aspect to be investigated is the use of the shape descriptors. If I have an efficient contour extraction technique I can use teeth labeling to identify the molars and then extract the contours of the molars. Since the upper molars have three roots and the lower molars are 2 roots figure 4.12, I can use shape descriptors [gonza02] to classify the dental bitewing images.

Further above mentioned refinement in the classification techniques may yield speedy and efficient classification. 


\section{REFERENCES}

[Ammar00] H. H Ammar, Y. Tao, "Fingerprint registration using genetic algorithms", Application-Specific Systems and Software Engineering Technology Proceedings. 3rd IEEE Symposium on, 24-25 (March 2000), Pages: $148-154$.

[Brown92] L.G. Brown, "A survey of image registration techniques", ACM Computing Surveys 24 (1992).

[Brogdon98] B.G. Brogdon, "Forensic Radiology", CRC Press, Boca Raton, 1998.

[CJIS00] CJIS Division - "Washington State Patrol Missing and Unidentified Person Unit”, Digitized Dental Images (Database), May 2000.

[CJIS02] CJIS Division - ADIS project, Digitized Radiographic Images (Database), August 2002.

[Duda00] R. O. Duda and P. E. Hart, "Pattern Classification and Scene Analysis", John Wiley \& Sons, New York, 2000.

[Gonza02] R.C. Gonzalez and R.E. Woods, "Digital Image Processing", 2nd ed., Prentice Hall, (2002).

[Jain86] A.K. Jain, "Fundamentals of Digital Image Processing", PrenticeHall, (1986).

[Jain99] A.K. Jain, Rudd Bolle, Sharath Pankanti, "Biometrics: Personal Identification in Networked Society", Kluwer Academic Publishers, (15 January 1999).

[Jain04] A.K. Jain and H. Chen, .Matching of Dental X-ray Images for Human Identification., Pattern Recognition, vol. 37, no. 7, Jul. 2004, pp. 1519-1532.

[Kneöaurek00] K. Kneöaurek, M. Ivanovic, J. Machac, D.A. Weber, "Medical image registration". Euro physics News (2000) Vol. 31 No. 4

[Kumar04] C. A. Kumar "A short text book of ORAL RADIOLOGY" Jaypee Borothers Medical Publishers (P) Ltd, India, 2004.

[Li06] X. Li, A. Abaza, D. Nassar, and H. Ammar, "Fast and Accurate Segmentation of Dental X-ray Records", to appear in Proc. 
ICBA 2006 (the 2006 International Conference onBiometric Authentication), Hong Kong, Jan. 2006.

[Mahoor05] M. Mahoor and Mohamed Abdel- Mottaleb, Automatic Classification of Teeth in Bitewing Images, Pattern Recognition, 38(2005), pp. 577586.

[McGiveney] J. McGivney et al. WinID software. http://www.winid.com

[Nassar01] D. Nassar, .A Prototype Automatic Dental Identification System (ADIS). Masters Thesis, Department of Electrical and Computer Engineering -WVU, Apr. 2001.

[Nassar02] D. Nassar, and H. Ammar, .A Neural Network based System for Dental Radiograph Comparison., 2nd IEEE International Symposium on Signal Processing and Information Technology (ISSPIT2002), Dec. 2002, Marrakech, Morocco.

[Nassar03] D. Nassar, H. Ammar, "A Prototype Automatic Dental Identification System" (ADIS), Department of Electrical and Computer Science Engineering - WVU. (March 2003).

[Nassar04] D. Nassar, F. Chaudhry, and H. Ammar, "On Performance Evaluation of Image Segmentation Algorithms: Success is Not All or None", Proc. the 1st International Computer Engineering Conference (ICENCO’ 2004), pp. 354-359, Egypt, Dec. 2004.

[Nassar05] D. Nassar, M. Ogirala, Z. Millwala, D. Adjeroh and H.Ammar, "Bounds on Image Alignment Parameters under Affine Transformation", Submitted to ICASSP 2005.

[Nomair05] O. Nomair and M. Abdel-Mottaleb, "A system for human identification from X-ray dental radiographs", Pattern Recognition, 38(2005), pp. 1295-1305.

[Odont] American society of forensic odontology, Forensic Odontol. News 16(2).

[RM03] West Virginia University Research Corporation-West Virginia University (2003).

[Samad04] F. Samadzadegan, F. Bashizadeh, M. Hahn, P. Ramzi, "Automatic Registration of Dental Radiograms", Geo-Imagery Bridging Continents, Commission 5, XX ISPRS Congress, 12-23 (July 2004) Istanbul, Turkey. 
[Said06] E. Said, D. Nassar, and H. Ammar, "Image segmentation for automated dental identification", to appear in Proc. of the 2006 SPIE Electronic Imaging.

[Southard96] T.E. Southard and K.A. Southard, "Detection of simulated osteoporosis in maxillae using radiographic texture analysis", Biomedical Engineering, IEEE Transactions on Volume 43, Issue 2, Feb. 1996 Page(s): 123 - 132 Digital Object Identifier $10.1109 / 10.481981$

[U.S Army90] United States Army Institute of Dental Research Walter Reed Army Medical Center, "Computer Assisted Post Mortem Identification via Dental and other Characteristics", USAIDR Information Bulletin, vol. 5, no. 1, Autumn 1990.

[Zhou05] J. Zhou, and M. Abdel-Mottaleb, "A Content-based System for Human Identification based on Bitewing Dental X-Ray Images", Pattern Recognition, 38(2005), pp. 2132-2142. 


\section{APPENDIXES}

\section{APPENDEX A: Training Set For Mandibular Jaw}

\begin{tabular}{|c|c|c|c|c|c|c|}
\hline Class Label & Mean & $\begin{array}{l}\text { Standard } \\
\text { Deviation }\end{array}$ & Smoothness & Skewness & Uniformity & Entropy \\
\hline lower & 147.2383 & 4.1093 & 0.0003 & 0.0002 & 0.086 & 3.8834 \\
\hline lower & 150.3 & 6.7169 & 0.0009 & -0.0014 & 0.0561 & 4.4405 \\
\hline lower & 71.0217 & 11.2405 & 0.0021 & 0.0111 & 0.0316 & 5.2419 \\
\hline lower & 95.8375 & 12.1397 & 0.0024 & -0.0014 & 0.0288 & 5.3671 \\
\hline lower & 100.585 & 7.6642 & 0.0009 & 0.0007 & 0.04 & 4.8325 \\
\hline lower & 73.1175 & 10.3323 & 0.0017 & -0.0029 & 0.0308 & 5.2582 \\
\hline lower & 70.4727 & 8.9994 & 0.0014 & -0.0019 & 0.0478 & 4.8756 \\
\hline lower & 80.379 & 10.5035 & 0.0017 & 0.0056 & 0.0376 & 5.0306 \\
\hline lower & 97.8442 & 7.1293 & 0.0013 & -0.0214 & 0.1017 & 4.0329 \\
\hline lower & 92.6458 & 5.0206 & 0.0004 & -0.0013 & 0.0745 & 4.0774 \\
\hline lower & 110.4996 & 8.3447 & 0.0012 & -0.0036 & 0.0463 & 4.8392 \\
\hline lower & 144.86 & 5.2935 & 0.0005 & 0.0012 & 0.0832 & 4.1212 \\
\hline lower & 124.8392 & 7.2146 & 0.001 & -0.0037 & 0.0732 & 4.2711 \\
\hline lower & 119.3808 & 8.8082 & 0.0013 & -0.0014 & 0.038 & 4.8976 \\
\hline lower & 96.5783 & 4.5116 & 0.0003 & 0.0015 & 0.0777 & 3.9803 \\
\hline lower & 96.2342 & 4.995 & 0.0004 & 0.0011 & 0.0638 & 4.2138 \\
\hline lower & 111.2292 & 10.7632 & 0.0019 & 0.0231 & 0.0368 & 5.097 \\
\hline lower & 49.2492 & 7.2162 & 0.001 & -0.0014 & 0.0552 & 4.5308 \\
\hline lower & 41.7692 & 6.9415 & 0.0008 & 0.0024 & 0.0493 & 4.6385 \\
\hline lower & 64.5771 & 9.5737 & 0.0015 & 0.0013 & 0.0351 & 5.143 \\
\hline lower & 80.3233 & 11.6047 & 0.0021 & 0.0019 & 0.027 & 5.3932 \\
\hline lower & 58.9377 & 8.8643 & 0.0012 & 0.0069 & 0.038 & 4.9753 \\
\hline lower & 121.105 & 9.7946 & 0.002 & -0.0035 & 0.0416 & 4.9549 \\
\hline lower & 108.9308 & 8.3436 & 0.0012 & 0.0046 & 0.0393 & 4.8956 \\
\hline lower & 92.4442 & 5.9464 & 0.0006 & 0.0022 & 0.056 & 4.4497 \\
\hline lower & 132.665 & 7.8305 & 0.0011 & -0.0075 & 0.0431 & 4.7806 \\
\hline lower & 153.12 & 12.1294 & 0.0025 & 0.0157 & 0.0291 & 5.3657 \\
\hline lower & 98.3383 & 9.0231 & 0.0015 & 0.0076 & 0.0416 & 4.8657 \\
\hline lower & 75.9725 & 14.7717 & 0.0038 & 0.068 & 0.0308 & 5.4084 \\
\hline lower & 80.0817 & 23.4925 & 0.0087 & -0.0346 & 0.0198 & 5.9478 \\
\hline lower & 91.1542 & 16.0655 & 0.0048 & 0.047 & 0.0264 & 5.5893 \\
\hline lower & 84.8 & 6.0531 & 0.0006 & 0.0007 & 0.0529 & 4.5058 \\
\hline lower & 109.1702 & 10.7841 & 0.002 & 0.0313 & 0.0346 & 5.174 \\
\hline lower & 108.5392 & 11.5631 & 0.0022 & -0.0018 & 0.0286 & 5.4095 \\
\hline lower & 108.3165 & 5.521 & 0.0005 & 0.0013 & 0.0662 & 4.3202 \\
\hline lower & 119.0575 & 7.3577 & 0.0008 & 0.0062 & 0.0503 & 4.6882 \\
\hline lower & 114.1685 & 7.5937 & 0.001 & 0.0095 & 0.0535 & 4.6384 \\
\hline lower & 104.3544 & 4.8272 & 0.0004 & 0.0006 & 0.0749 & 4.1251 \\
\hline lower & 86.77 & 13.5672 & 0.0028 & -0.0019 & 0.0245 & 5.5781 \\
\hline
\end{tabular}




$\begin{array}{lrrrrrr}\text { lower } & 94.27 & 6.9909 & 0.0009 & 0.0012 & 0.0472 & 4.6072 \\ \text { lower } & 39.2608 & 6.5006 & 0.0007 & 0.0027 & 0.0508 & 4.5129 \\ \text { lower } & 27.3825 & 7.0812 & 0.0008 & 0.0048 & 0.0806 & 4.3828 \\ \text { lower } & 138.8592 & 13.3739 & 0.0029 & 0.0161 & 0.0263 & 5.4964 \\ \text { lower } & 75.15 & 9.2845 & 0.0014 & -0.0068 & 0.0361 & 5.0519 \\ \text { lower } & 60.6533 & 4.7136 & 0.0003 & -0.0001 & 0.0629 & 4.2044 \\ \text { lower } & 67.0108 & 7.5295 & 0.0009 & 0.005 & 0.0453 & 4.7423 \\ \text { lower } & 91.7383 & 9.4281 & 0.0018 & 0.0126 & 0.042 & 4.8891 \\ \text { lower } & 81.5733 & 6.6867 & 0.0008 & 0.0014 & 0.0509 & 4.5719 \\ \text { lower } & 57.5275 & 8.4205 & 0.0011 & 0.0059 & 0.0398 & 4.8893 \\ \text { lower } & 51.4002 & 10.3782 & 0.0017 & 0.0066 & 0.0295 & 5.2817\end{array}$




\section{APPENDEX B: Training Set For Maxillary Jaw}

\begin{tabular}{|c|c|c|c|c|c|c|}
\hline $\begin{array}{l}\text { Class } \\
\text { Label }\end{array}$ & Mean & $\begin{array}{l}\text { Standard } \\
\text { Deviation }\end{array}$ & Smoothness & Skewness & Uniformity & Entropy \\
\hline upper & 125.8967 & 13.7861 & 0.0032 & 0.0121 & 0.0273 & 5.4834 \\
\hline upper & 93.2125 & 15.5467 & 0.0038 & 0.025 & 0.027 & 5.5494 \\
\hline upper & 118.6263 & 6.8125 & 0.0007 & 0.0029 & 0.0556 & 4.5091 \\
\hline upper & 131.6769 & 9.553 & 0.0015 & 0.0066 & 0.0373 & 5.0283 \\
\hline upper & 130.02 & 7.3148 & 0.0009 & -0.0054 & 0.0534 & 4.5633 \\
\hline upper & 142.8967 & 6.1368 & 0.0006 & -0.0014 & 0.0561 & 4.3657 \\
\hline upper & 131.2758 & 14.3476 & 0.0036 & 0.0106 & 0.0321 & 5.3062 \\
\hline upper & 118.4108 & 8.029 & 0.001 & -0.0011 & 0.0414 & 4.8066 \\
\hline upper & 93.8875 & 4.2042 & 0.0004 & 0.0016 & 0.1303 & 3.5451 \\
\hline upper & 106.5077 & 19.8504 & 0.0061 & 0.0616 & 0.0209 & 5.9333 \\
\hline upper & 92.6604 & 16.703 & 0.0049 & 0.2125 & 0.0317 & 5.4035 \\
\hline upper & 33.4498 & 17.4901 & 0.0065 & 0.1524 & 0.0325 & 5.4888 \\
\hline upper & 99.6327 & 15.9903 & 0.0039 & -0.0199 & 0.0221 & 5.7757 \\
\hline upper & 97.5098 & 20.0029 & 0.0068 & -0.0075 & 0.0176 & 6.0476 \\
\hline upper & 97.106 & 27.1086 & 0.0137 & 0.1599 & 0.0266 & 5.9594 \\
\hline upper & 29.6717 & 14.4134 & 0.0039 & 0.1508 & 0.0455 & 5.0389 \\
\hline upper & 53.8944 & 15.0793 & 0.0038 & 0.0041 & 0.0382 & 5.3526 \\
\hline upper & 186.73 & 3.2326 & 0.0002 & 0.0001 & 0.1055 & 3.545 \\
\hline upper & 183.3792 & 5.8769 & 0.0005 & -0.0013 & 0.0567 & 4.3321 \\
\hline upper & 120.6208 & 14.4344 & 0.0035 & 0.0262 & 0.0312 & 5.3957 \\
\hline upper & 85.93 & 9.7799 & 0.0015 & 0.0062 & 0.0331 & 5.1376 \\
\hline upper & 140.2958 & 5.4745 & 0.0005 & 0 & 0.0607 & 4.2773 \\
\hline upper & 137.1217 & 8.2076 & 0.0011 & 0.0086 & 0.0442 & 4.7853 \\
\hline upper & 123.2875 & 12.1625 & 0.0025 & 0.0186 & 0.0321 & 5.326 \\
\hline upper & 136.1717 & 17.3996 & 0.0054 & -0.043 & 0.0268 & 5.5884 \\
\hline upper & 119.8358 & 12.3397 & 0.0024 & -0.0142 & 0.0272 & 5.478 \\
\hline upper & 88.9692 & 21.3347 & 0.007 & -0.047 & 0.0205 & 5.9222 \\
\hline upper & 113.6142 & 14.9913 & 0.0043 & 0.0183 & 0.0327 & 5.3565 \\
\hline upper & 152.0483 & 13.0117 & 0.0026 & -0.0066 & 0.0267 & 5.4675 \\
\hline upper & 112.7573 & 10.1823 & 0.0016 & 0.0089 & 0.0329 & 5.2317 \\
\hline upper & 120.5938 & 13.4428 & 0.0028 & 0.0074 & 0.0239 & 5.5597 \\
\hline upper & 118.0979 & 11.6485 & 0.0021 & 0.0021 & 0.0262 & 5.4167 \\
\hline upper & 118.0979 & 11.6485 & 0.0021 & 0.0021 & 0.0262 & 5.4167 \\
\hline upper & 109.4458 & 16.4717 & 0.0045 & -0.0933 & 0.027 & 5.5338 \\
\hline upper & 47.4075 & 14.4188 & 0.0032 & 0.018 & 0.0226 & 5.7243 \\
\hline upper & 101.8175 & 16.6803 & 0.006 & -0.0868 & 0.0306 & 5.4465 \\
\hline upper & 84.5775 & 14.1325 & 0.0032 & 0.0197 & 0.024 & 5.5355 \\
\hline upper & 175.0242 & 7.5157 & 0.001 & -0.0045 & 0.0553 & 4.4778 \\
\hline upper & 118.3233 & 17.4066 & 0.005 & -0.0011 & 0.023 & 5.7308 \\
\hline upper & 104.825 & 11.7088 & 0.0023 & 0.0304 & 0.0322 & 5.2394 \\
\hline upper & 151.729 & 17.8869 & 0.005 & 0.0062 & 0.018 & 6.0066 \\
\hline upper & 103.2433 & 11.1827 & 0.002 & 0.0058 & 0.0305 & 5.3003 \\
\hline upper & 68.1942 & 9.1739 & 0.0016 & -0.0013 & 0.0549 & 4.6603 \\
\hline upper & 75.8 & 22.1388 & 0.0077 & 0.0253 & 0.0146 & 6.3191 \\
\hline
\end{tabular}




$\begin{array}{lrrrrrr}\text { upper } & 91.7475 & 11.7432 & 0.0023 & 0.0398 & 0.0342 & 5.1875 \\ \text { upper } & 128.0846 & 9.7615 & 0.0016 & 0.004 & 0.0327 & 5.1447 \\ \text { upper } & 105.9275 & 5.8289 & 0.0006 & 0.0032 & 0.0547 & 4.4122 \\ \text { upper } & 77.8012 & 16.1685 & 0.0043 & 0.004 & 0.0216 & 5.7903 \\ \text { upper } & 148.9077 & 19.2929 & 0.0059 & 0.0728 & 0.0256 & 5.6656 \\ \text { upper } & 171.56 & 16.351 & 0.0051 & -0.0943 & 0.0257 & 5.6409 \\ \text { upper } & 123.6502 & 12.5284 & 0.0027 & 0.0096 & 0.0253 & 5.5037\end{array}$




\section{APPENDEX C: Test Set For Mandibular Jaw}

\begin{tabular}{|c|c|c|c|c|c|c|}
\hline Label & Mean & $\begin{array}{l}\text { Standarad } \\
\text { Devaition }\end{array}$ & Smoothness & Skewness & Uniformity & Entropy \\
\hline wer & 149.5758 & 8.7679 & 0.0012 & -0.0039 & 0.0354 & 5.0548 \\
\hline lower & 120.915 & 4.2617 & 0.0003 & 0.0004 & 0.0788 & 3.9373 \\
\hline wer & 195.7282 & 19.3983 & 0.0061 & -0.0923 & 0.019 & 6.0043 \\
\hline lower & 127.4683 & 8.762 & 0.0012 & 0.0048 & 0.0368 & 4.9668 \\
\hline lower & 123.6898 & 6.5289 & 0.0007 & 0.0051 & 0.0522 & 4.5522 \\
\hline lower & 51.1069 & 6.4986 & 0.0007 & 0.0063 & 0.0527 & 4.5114 \\
\hline lower & 81.2503 & 6.6726 & 0.0007 & 0.001 & 0.0525 & 4.48 \\
\hline lower & 123.9412 & 8.5804 & 0.0011 & 0.0088 & 0.0388 & 4.9575 \\
\hline lower & 42.2996 & 8.6897 & 0.0012 & 0.0049 & 0.056 & 4.4345 \\
\hline lower & 29.4291 & 8.8979 & 0.0013 & 0.0128 & 0.0773 & 4.1152 \\
\hline lower & 79.9606 & 4.4738 & 0.0003 & 0.0003 & 0.0662 & 4.1443 \\
\hline lower & 130.6161 & 5.8659 & 0.0005 & 0.0035 & 0.0611 & 4.3344 \\
\hline lower & 57.7826 & 6.1265 & 0.0008 & 0.0017 & 0.0617 & 4.3714 \\
\hline lower & 79.8876 & 6.0761 & 0.0006 & 0.0017 & 0.0505 & 4.5355 \\
\hline lower & 41.8805 & 7.3758 & 0.0009 & 0.0029 & 0.0456 & 4.7328 \\
\hline lower & 22.3359 & 8.7545 & 0.0012 & 0.0047 & 0.0453 & 4.8169 \\
\hline lower & 79.4169 & 9.3603 & 0.0021 & 0.0019 & 0.0474 & 5.1831 \\
\hline lower & 80.5197 & 9.8865 & 0.0017 & 0.0102 & 0.0395 & 5.0752 \\
\hline lower & 130.7916 & 15.4714 & 0.0037 & -0.0395 & 0.0226 & 5.7396 \\
\hline lower & 73.1195 & 21.7033 & 0.0073 & 0.1195 & 0.018 & 6.0854 \\
\hline lower & 42.1347 & 10.7621 & 0.0019 & 0.0356 & 0.0368 & 5.1058 \\
\hline lower & 104.5328 & 7.7604 & 0.0012 & -0.0016 & 0.0568 & 4.4867 \\
\hline lower & 161.3429 & 13.3952 & 0.0029 & 0.0002 & 0.0238 & 5.5897 \\
\hline lower & 81.6405 & 15.4969 & 0.0042 & 0.0293 & 0.0314 & 5.1489 \\
\hline lower & 108.8309 & 19.6513 & 0.0061 & 0.0161 & 0.0238 & 5.2886 \\
\hline lower & 112.4651 & 19.6436 & 0.0062 & 0.0 & 0.0223 & 5.3322 \\
\hline lower & 66.2832 & 8.6527 & 0.0012 & 0.0039 & 0.0376 & 4.9764 \\
\hline lower & 71.0352 & 11.7884 & 0.0022 & -0.0023 & 0.0288 & 5.3458 \\
\hline lower & 77.9701 & 14.2411 & 0.0034 & 0.0126 & 0.024 & 5.6219 \\
\hline lower & 84.5397 & 7.5463 & 0.001 & 0.0189 & 0.0588 & 4.4801 \\
\hline lower & 101.8038 & 10.447 & 0.0018 & 0.0202 & 0.0363 & 5.1565 \\
\hline lower & 106.7665 & 12.3772 & 0.0024 & 0.032 & 0.036 & 5.2563 \\
\hline lower & 104.6549 & 9.883 & 0.0016 & 0.0057 & 0.0326 & 5.1669 \\
\hline lower & 94.6197 & 8.869 & 0.0013 & 0.0063 & 0.0358 & 5.01 \\
\hline lower & 187.1019 & 6.4358 & 0.0007 & -0.0006 & 0.0477 & 4.6206 \\
\hline lower & 195.5072 & 8.306 & 0.0011 & 0.0024 & 0.0376 & 4.965 \\
\hline lower & 142.0629 & 8.7511 & 0.0013 & 0.0065 & 0.0404 & 4.9194 \\
\hline lower & 137.4336 & 18.7308 & 0.0056 & -0.0034 & 0.0239 & 5.6393 \\
\hline lower & 155.9317 & 18.2296 & 0.0056 & -0.0563 & 0.0236 & 5.7334 \\
\hline lower & 117.0197 & 8.5223 & 0.0012 & 0.0077 & 0.0406 & 4.9261 \\
\hline wer & 122.4123 & 8.843 & 0.0015 & 0.0265 & 0.0513 & 4.728 \\
\hline wer & 33.1461 & 5.9491 & 0.0006 & 0.0045 & 0.0714 & 4.2219 \\
\hline lower & 92.9979 & 11.1272 & 0.0019 & 0.0083 & 0.0279 & 5.351 \\
\hline
\end{tabular}




\begin{tabular}{|c|c|c|c|c|c|c|}
\hline lower & 124.8640 & 15.1522 & 0.0037 & -0.0292 & 0.0223 & 5.7416 \\
\hline lower & 128.1291 & 13.0991 & 0.0029 & -0.0155 & 0.026 & 5.4773 \\
\hline lower & 168.6112 & 7.198 & 0.0008 & -0.0003 & 0.0429 & 4.773 \\
\hline lower & 173.1760 & 9.3276 & 0.0014 & 0.0029 & 0.0345 & 5.10 \\
\hline lower & 165.4016 & 7.1781 & 0.0008 & 0.0009 & 0.044 & 4.7 \\
\hline lower & 89.9115 & 10.9826 & 0.002 & 0.0209 & 0.0314 & 5.2 \\
\hline lower & 98.6683 & 9.9248 & 0.0016 & 0.007 & 0.034 & 5.10 \\
\hline lower & 42.36 & 3.7226 & 0.0002 & 0.0005 & 0.0841 & 3.78 \\
\hline lower & 48.216 & 3.7272 & 0.0003 & 0.0023 & 0.1693 & 3.24 \\
\hline lower & 69.9477 & 7.8259 & 0.0011 & 0.0014 & 0.0422 & 4.79 \\
\hline lower & 77.088 & 14.2075 & 0.0035 & 0.062 & 0.0319 & 5.45 \\
\hline lower & 90.3557 & 11.2992 & 0.0021 & 0.0177 & 0.0343 & 5.19 \\
\hline lower & 79.8064 & 9.0729 & 0.0013 & -0.0005 & 0.0338 & 5.06 \\
\hline lower & 133.1717 & 11.8874 & 0.0022 & 0.0081 & 0.0276 & 5.43 \\
\hline lower & 28.1547 & 13.5814 & 0.0036 & 0.0532 & 0.0491 & 4 \\
\hline lower & 19.0432 & 20.7468 & 0.0079 & 0.1988 & 0.1823 & 4.3 \\
\hline lower & 5.328 & 9.1843 & 0.0022 & 0.1091 & 0.4856 & \\
\hline lower & 13.1797 & 1.9855 & 0.0001 & 0.0002 & 0.1929 & 2.71 \\
\hline lower & 25.6253 & 6.7031 & 0.0007 & 0.0046 & 0.0568 & 4.50 \\
\hline lower & 14.2357 & 2.8344 & 0.0002 & 0.0008 & 0.1685 & 3.05 \\
\hline lower & 149.1758 & 13.5764 & 0.0029 & 0.0288 & 0.0282 & 5.47 \\
\hline lower & 81.0325 & 5.6132 & 0.0005 & -0.002 & 0.0577 & 4.347 \\
\hline lower & 95.085 & 16.6393 & 0.0044 & 0.0562 & 0.0217 & 5.78 \\
\hline lower & 177.0242 & 18.8881 & 0.0064 & -0.1039 & 0.0237 & 5.68 \\
\hline lower & 65.5525 & 42.1265 & 0.0493 & 1.5559 & 0.1096 & 4.3 \\
\hline lower & 53.7425 & 8.6885 & 0.0014 & 0.0248 & 0.0955 & 4.13 \\
\hline lower & 137.9575 & 12.6112 & 0.0025 & 0.0042 & 0.0259 & 5.45 \\
\hline lower & 138.3904 & 3.8311 & 0.0002 & 0.0004 & 0.0849 & 3.816 \\
\hline lower & 145.5167 & 5.7309 & 0.0006 & -0.0005 & 0.0698 & 4.2 \\
\hline lower & 145.3669 & 3.2653 & 0.0002 & -0.0005 & 0.1059 & 3.57 \\
\hline lower & 143.134 & 5.6944 & 0.0007 & -0.0021 & 0.1074 & 3.8 \\
\hline lower & 105.1733 & 14.2988 & 0.0033 & 0.019 & 0.0245 & 5.603 \\
\hline lower & 153.4967 & 7.1701 & 0.0008 & -0.0019 & 0.0461 & $4.71 \varepsilon$ \\
\hline lower & 113.9683 & 11.7337 & 0.0022 & -0.0025 & 0.0269 & 5.43 \\
\hline lower & 172.3417 & 10.6994 & 0.0019 & -0.01 & 0.0321 & 5.23 \\
\hline lower & 129.4833 & 15.6026 & 0.0042 & -0.006 & 0.024 & 5.62 \\
\hline lower & 51.1283 & 4.4058 & 0.0003 & 0.0028 & 0.0863 & 3.84 \\
\hline lower & 51.6342 & 4.0136 & 0.0003 & 0.0007 & 0.0902 & 3.79 \\
\hline lower & 62.1558 & 27.037 & 0.0129 & 0.1 & 0.0309 & $5.80 ?$ \\
\hline lower & 43.4783 & 16.2084 & 0.0042 & 0.0743 & 0.0318 & 5.40 \\
\hline lower & 117.7075 & 11.9639 & 0.0024 & 0.0217 & 0.0334 & 5.19 \\
\hline lower & 155.1092 & 6.3923 & 0.0007 & -0.0011 & 0.0539 & 4.4 \\
\hline lower & 114.2635 & 12.4614 & 0.0026 & -0.0271 & 0.0286 & 5.46 \\
\hline lower & 109.4919 & 14.6608 & 0.0036 & -0.0459 & 0.0252 & 5.64 \\
\hline lower & 150.1217 & 4.6618 & 0.0003 & -0.0003 & 0.0695 & 4.12 \\
\hline lower & 132.5083 & 6.7108 & 0.0008 & -0.0042 & 0.0593 & 4. \\
\hline lower & 104.3483 & 7.9546 & 0.001 & 0.0007 & 0.0454 & 4.72 \\
\hline lower & 123.38 & 10.6511 & 0.002 & 0.0016 & 0.0348 & 5. \\
\hline lower & 136.6267 & 7.0312 & 0.0008 & 0.0013 & 0.0462 & 4.69 \\
\hline lower & 114.845 & 6.1007 & 0.0006 & 0.0002 & 0.0573 & 4.45 \\
\hline
\end{tabular}




$\begin{array}{lrrrrrr}\text { lower } & 97.655 & 6.0524 & 0.0006 & 0 & 0.0553 & 4.4678 \\ \text { lower } & 101.6458 & 4.06 & 0.0003 & -0.0009 & 0.1047 & 3.6275\end{array}$




\section{APPENDEX D: Test Set For Maxillary Jaw}

\begin{tabular}{|c|c|c|c|c|c|c|}
\hline Class Label & Mean & $\begin{array}{l}\text { Standard } \\
\text { Deviation }\end{array}$ & Smoothness & Skewness & Uniformity & Entropy \\
\hline upper & 147.0571 & 11.5068 & 0.0022 & 0.0176 & 0.0296 & 5.3575 \\
\hline upper & 147.9442 & 11.2293 & 0.0026 & -0.0647 & 0.0388 & 4.995 \\
\hline upper & 116.525 & 3.5853 & 0.0002 & 0.0006 & 0.1223 & 3.5289 \\
\hline upper & 170.3401 & 19.2623 & 0.0058 & -0.0307 & 0.0276 & 5.8445 \\
\hline upper & 186.7717 & 9.1821 & 0.0014 & -0.0092 & 0.0363 & 5.0674 \\
\hline upper & 116.0101 & 5.3327 & 0.0004 & 0.0001 & 0.0558 & 4.3769 \\
\hline upper & 114.0052 & 14.4279 & 0.0033 & 0.0128 & 0.0239 & 5.5625 \\
\hline upper & 147.1205 & 19.2446 & 0.0057 & 0.0314 & 0.0206 & 5.908 \\
\hline upper & 143.0267 & 19.2346 & 0.0058 & 0.0168 & 0.0177 & 6.0789 \\
\hline upper & 88.1633 & 11.1897 & 0.0021 & -0.007 & 0.032 & 5.1823 \\
\hline upper & 69.0645 & 9.1674 & 0.0014 & 0.0011 & 0.0337 & 5.1067 \\
\hline upper & 104.221 & 22.3156 & 0.0079 & 0.0838 & 0.0292 & 5.3697 \\
\hline upper & 81.505 & 10.1357 & 0.0016 & 0.0028 & 0.0426 & 4.9019 \\
\hline upper & 109.0498 & 10.4061 & 0.0017 & -0.0022 & 0.03 & 5.2984 \\
\hline upper & 70.8623 & 6.0479 & 0.0007 & 0.0023 & 0.0746 & 4.299 \\
\hline upper & 63.0294 & 13.2448 & 0.0033 & 0.0874 & 0.044 & 5.0265 \\
\hline upper & 67.3649 & 12.444 & 0.0026 & 0.0364 & 0.0356 & 5.2574 \\
\hline upper & 62.9584 & 14.9409 & 0.0038 & 0.0297 & 0.023 & 5.7102 \\
\hline upper & 79.3676 & 14.5067 & 0.0033 & 0.0202 & 0.0236 & 5.6357 \\
\hline upper & 86.2708 & 12.7431 & 0.0035 & 0.0676 & 0.0376 & 5.1032 \\
\hline upper & 98.6667 & 16.6777 & 0.005 & 0.062 & 0.0255 & 5.656 \\
\hline upper & 153.4042 & 15.6151 & 0.004 & 0.0266 & 0.0258 & 5.5573 \\
\hline upper & 156.7208 & 15.2055 & 0.004 & -0.0043 & 0.0277 & 5.5443 \\
\hline upper & 189.1442 & 11.6207 & 0.0022 & -0.005 & 0.032 & 5.2534 \\
\hline upper & 128.6525 & 12.9302 & 0.0026 & 0.0207 & 0.03 & 5.3846 \\
\hline upper & 138.3117 & 10.9655 & 0.0019 & -0.0009 & 0.0384 & 5.0942 \\
\hline upper & 153.192 & 8.6461 & 0.0012 & 0.0067 & 0.0439 & 4.8631 \\
\hline upper & 129.2016 & 12.7158 & 0.0029 & 0.0376 & 0.0344 & 5.2769 \\
\hline upper & 94.8507 & 10.678 & 0.0018 & 0.0077 & 0.0314 & 5.2328 \\
\hline upper & 170.3472 & 24.3639 & 0.0095 & -0.0244 & 0.015 & 6.2482 \\
\hline upper & 167.52 & 24.9043 & 0.0099 & -0.0021 & 0.015 & 6.2614 \\
\hline upper & 89.7275 & 12.416 & 0.0026 & -0.0139 & 0.0328 & 5.2492 \\
\hline upper & 102.8341 & 14.0328 & 0.0031 & 0.0147 & 0.0261 & 5.5025 \\
\hline upper & 105.5307 & 17.2541 & 0.0047 & 0.0458 & 0.0198 & 5.882 \\
\hline upper & 116.2731 & 14.5755 & 0.0035 & 0.0068 & 0.0246 & 5.6351 \\
\hline upper & 118.6427 & 9.8941 & 0.0015 & 0.0049 & 0.0307 & 5.2284 \\
\hline upper & 131.9787 & 18.3376 & 0.0063 & -0.0989 & 0.0218 & 5.8147 \\
\hline upper & 132.3232 & 15.6481 & 0.0048 & -0.0371 & 0.0236 & 5.6473 \\
\hline upper & 182.5915 & 11.5908 & 0.0023 & 0.0005 & 0.0321 & 5.2558 \\
\hline upper & 75.9813 & 13.7399 & 0.0032 & 0.0535 & 0.0289 & 5.4565 \\
\hline upper & 126.0501 & 13.0576 & 0.002 & 0.017 & 0.025 & 5.5474 \\
\hline upper & 155.5877 & 4.9146 & 0.0004 & -0.0018 & 0.068 & 4.1357 \\
\hline upper & 129.3141 & 11.4278 & 0.0021 & -0.0095 & 0.0326 & 5.2368 \\
\hline
\end{tabular}




\begin{tabular}{|c|c|c|c|c|c|c|}
\hline upper & 138.7765 & 13.5554 & 0.0028 & -0.0096 & 0.0261 & 5.4629 \\
\hline upper & 162.7403 & 10.7761 & 0.002 & -0.029 & 0.0386 & 5.0754 \\
\hline upper & 109.5947 & 16.223 & 0.0047 & 0.0782 & 0.0275 & 5.4986 \\
\hline upper & 76.7019 & 18.9917 & 0.0073 & -0.0905 & 0.0248 & 5.7581 \\
\hline upper & 76.1013 & 12.2224 & 0.0025 & -0.0072 & 0.0407 & 5.1998 \\
\hline upper & 74.0208 & 25.1393 & 0.0118 & 0.2476 & 0.02 & 6.0469 \\
\hline upper & 192.6229 & 16.5022 & 0.0043 & 0.0091 & 0.0203 & 5.9054 \\
\hline upper & 92.5621 & 35.7516 & 0.0234 & -1.4717 & 0.0321 & 5.6976 \\
\hline upper & 47.0341 & 28.4861 & 0.0142 & -0.2357 & 0.2474 & 4.7893 \\
\hline upper & 57.9893 & 42.2732 & 0.0269 & 0.2447 & 0.0267 & 6.3344 \\
\hline upper & 118.408 & 18.7197 & 0.0064 & 0.0316 & 0.0239 & 5.7585 \\
\hline upper & 44.1812 & 20.8359 & 0.0077 & 0.1389 & 0.0255 & 5.786 \\
\hline upper & 36.5402 & 15.5579 & 0.0041 & 0.1125 & 0.0386 & 5.2508 \\
\hline upper & 65.2917 & 7.4235 & 0.0009 & 0.0019 & 0.0495 & 4.6544 \\
\hline upper & 66.2942 & 21.7611 & 0.0073 & -0.0329 & 0.0287 & 5.6679 \\
\hline upper & 80.8983 & 12.9343 & 0.0029 & -0.009 & 0.0408 & 5.1484 \\
\hline upper & 161.8242 & 8.5919 & 0.0013 & 0.0031 & 0.046 & 4.7439 \\
\hline upper & 97.2904 & 14.8832 & 0.0052 & -0.0034 & 0.0407 & 5.0202 \\
\hline upper & 133.3752 & 7.3699 & 0.0009 & -0.0021 & 0.0455 & 4.7308 \\
\hline upper & 148.1869 & 3.8014 & 0.0002 & -0.0006 & 0.0909 & 3.7621 \\
\hline upper & 179.8667 & 12.8223 & 0.0029 & -0.0089 & 0.0314 & 5.3522 \\
\hline upper & 149.3258 & 18.5442 & 0.0055 & 0.0075 & 0.0211 & 5.8697 \\
\hline upper & 126.1717 & 9.5549 & 0.0015 & -0.0098 & 0.035 & 5.0601 \\
\hline upper & 159.0142 & 19.2592 & 0.0077 & -0.0714 & 0.0244 & 5.7266 \\
\hline upper & 105.1717 & 18.6008 & 0.0054 & -0.0286 & 0.0182 & 5.964 \\
\hline upper & 125.4667 & 26.6371 & 0.0108 & -0.1078 & 0.0157 & 6.2809 \\
\hline upper & 163.32 & 15.8715 & 0.004 & -0.0072 & 0.0218 & 5.7218 \\
\hline upper & 61.9192 & 16.0096 & 0.0047 & -0.0392 & 0.0274 & 5.5513 \\
\hline upper & 57.5742 & 23.3529 & 0.0099 & 0.16 & 0.0203 & 5.9269 \\
\hline upper & 50.4283 & 16.5034 & 0.0049 & 0.1765 & 0.0327 & 5.3399 \\
\hline upper & 82.344 & 34.421 & 0.0185 & 0.0268 & 0.0147 & 6.5758 \\
\hline upper & 23.6742 & 3.2633 & 0.0002 & 0.0018 & 0.1161 & 3.4197 \\
\hline upper & 46.47 & 7.1585 & 0.0009 & -0.0003 & 0.0491 & 4.6202 \\
\hline upper & 54.2808 & 15.8279 & 0.0054 & -0.0179 & 0.0352 & 5.3632 \\
\hline upper & 68.309 & 29.8612 & 0.015 & -0.1024 & 0.0136 & 6.4163 \\
\hline upper & 51.5369 & 29.08 & 0.0137 & 0.5635 & 0.0216 & 6.0883 \\
\hline upper & 88.0548 & 31.639 & 0.0157 & 0.0302 & 0.0225 & 6.252 \\
\hline upper & 60.8042 & 13.2113 & 0.0037 & -0.0128 & 0.0698 & 4.9332 \\
\hline upper & 66.1854 & 18.5488 & 0.0067 & -0.0278 & 0.0433 & 5.4749 \\
\hline upper & 168.2458 & 13.2077 & 0.0028 & 0.0025 & 0.0254 & 5.5486 \\
\hline upper & 148.4975 & 12.031 & 0.0027 & -0.0079 & 0.0418 & 5.115 \\
\hline upper & 119.4752 & 17.0389 & 0.0045 & -0.0315 & 0.0184 & 5.9535 \\
\hline upper & 113.0383 & 12.7455 & 0.0026 & -0.024 & 0.0288 & 5.4119 \\
\hline upper & 142.1433 & 11.1941 & 0.0022 & 0.014 & 0.0328 & 5.1657 \\
\hline upper & 137.5142 & 6.1754 & 0.0006 & -0.0002 & 0.0642 & 4.3383 \\
\hline upper & 101.6733 & 6.4397 & 0.0007 & 0.0006 & 0.053 & 4.5429 \\
\hline upper & 90.1483 & 7.4561 & 0.0009 & -0.0028 & 0.0471 & 4.7197 \\
\hline upper & 95.1317 & 13.3416 & 0.0029 & -0.009 & 0.0311 & 5.3178 \\
\hline upper & 58.8567 & 6.788 & 0.0008 & 0.0039 & 0.0557 & 4.5022 \\
\hline upper & 148.8825 & 4.5165 & 0.0003 & 0.0002 & 0.0775 & 4.0081 \\
\hline
\end{tabular}


upper

upper
152.6925

87.415
3.8346

13.2373
0.0002

0.0028
$-0.001$

$-0.0241$
0.0828

0.0302
3.7898

5.3355 